\title{
A Comparison of Simulation Capabilities for Ducts
}

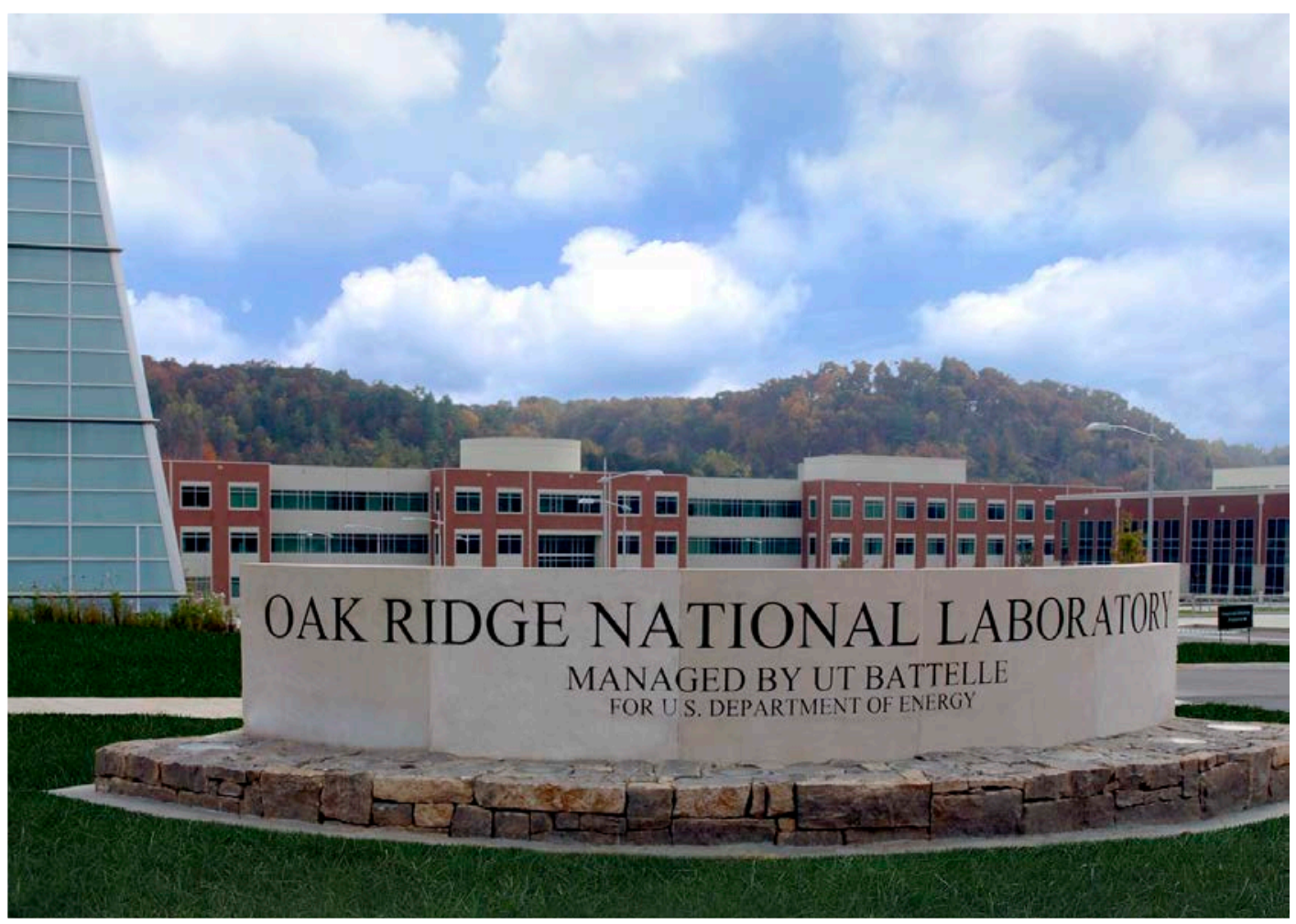

William A. Miller

Som Shrestha

Lixing $\mathrm{Gu}$

Ken Childs

Joshua New

September 2014 


\section{DOCUMENT AVAILABILITY}

Reports produced after January 1, 1996, are generally available free via the U.S. Department of Energy (DOE) Information Bridge.

Web site http://www.osti.gov/bridge

Reports produced before January 1, 1996, may be purchased by members of the public from the following source.

National Technical Information Service

5285 Port Royal Road

Springfield, VA 22161

Telephone 703-605-6000 (1-800-553-6847)

TDD 703-487-4639

Fax 703-605-6900

E-mail info@ntis.gov

Web site http://www.ntis.gov/support/ordernowabout.htm

Reports are available to DOE employees, DOE contractors, Energy Technology Data Exchange (ETDE) representatives, and International Nuclear Information System (INIS) representatives from the following source.

Office of Scientific and Technical Information

P.O. Box 62

Oak Ridge, TN 37831

Telephone 865-576-8401

Fax 865-576-5728

E-mail reports@osti.gov

Web site http://www.osti.gov/contact.html

This report was prepared as an account of work sponsored by an agency of the United States Government. Neither the United States Government nor any agency thereof, nor any of their employees, makes any warranty, express or implied, or assumes any legal liability or responsibility for the accuracy, completeness, or usefulness of any information, apparatus, product, or process disclosed, or represents that its use would not infringe privately owned rights. Reference herein to any specific commercial product, process, or service by trade name, trademark, manufacturer, or otherwise, does not necessarily constitute or imply its endorsement, recommendation, or favoring by the United States Government or any agency thereof. The views and opinions of authors expressed herein do not necessarily state or reflect those of the United States Government or any agency thereof. 


\title{
A Comparison of Simulation Capabilities for Ducts
}

\author{
William A. Miller \\ Som Shrestha \\ Lixing Gu \\ Ken Childs \\ Joshua New
}

September 2014

Prepared by

OAK RIDGE NATIONAL LABORATORY

Oak Ridge, Tennessee 37831-6283

managed by

UT-BATTELLE, LLC

for the

U.S. DEPARTMENT OF ENERGY

under contract DE-AC05-00OR22725 



\section{TABLE OF CONTENTS}

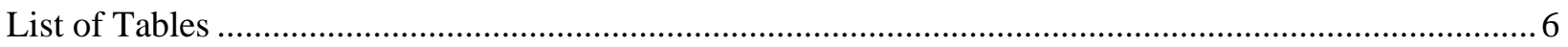

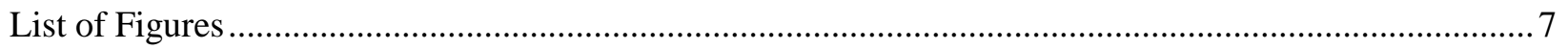

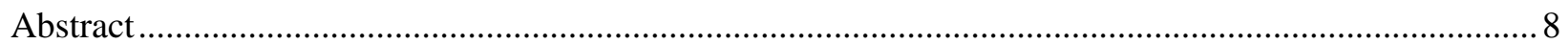

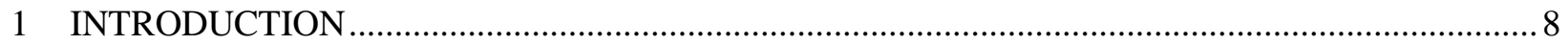

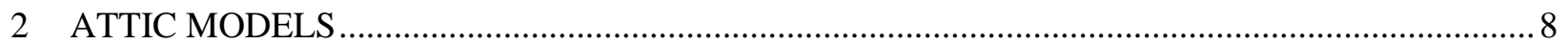

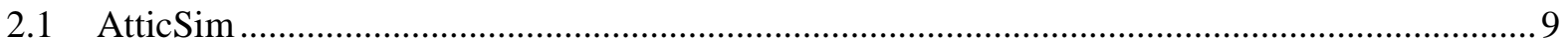

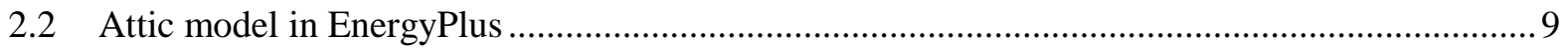

2.2.1 EnergyPlus’ Airflow Network (AFN) Description ....................................................... 9

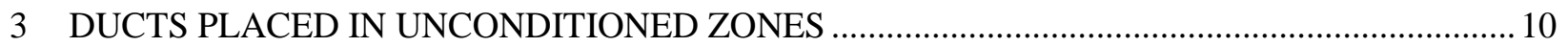

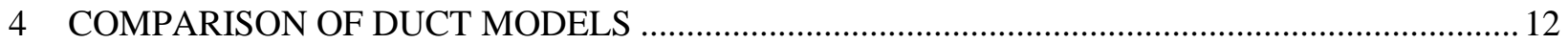

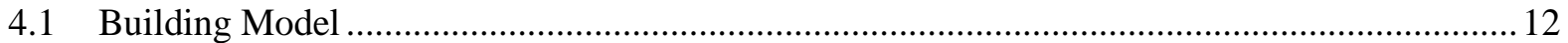

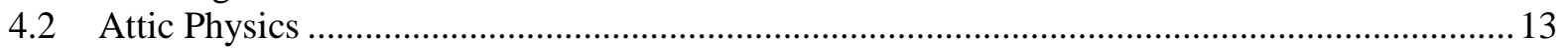

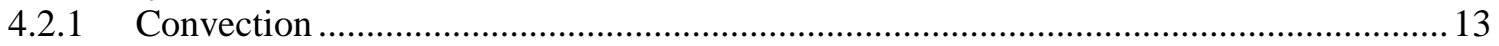

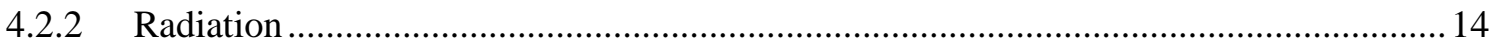

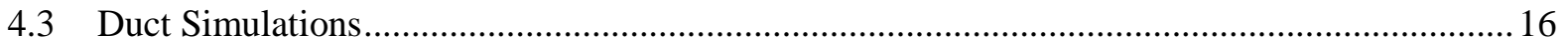

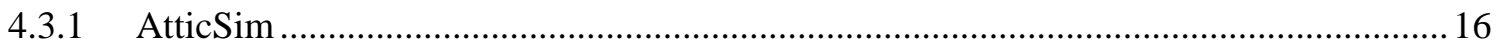

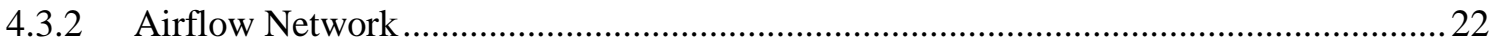

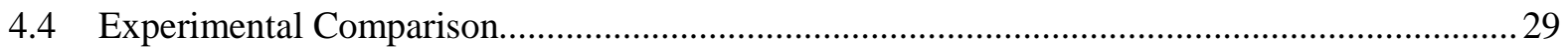

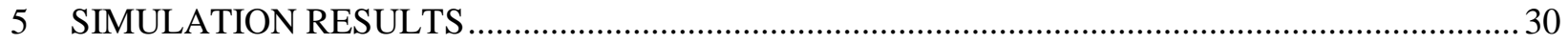

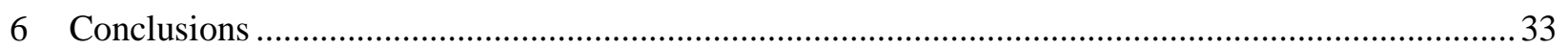

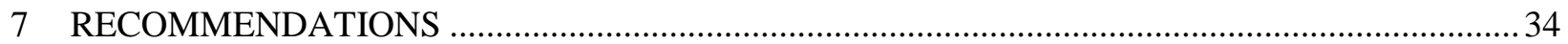

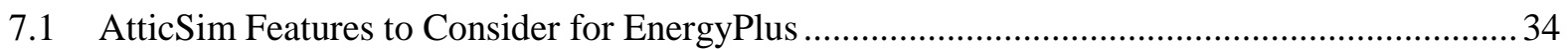

7.2 Items to enhance the Airflow Network model ........................................................................ 35

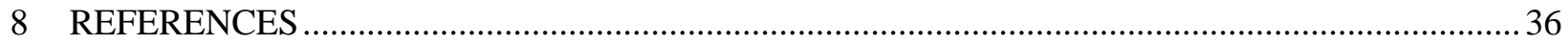

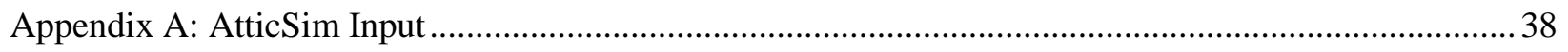

Appendix B: Model Comparison Between AtticSim and EnergyPlus....................................................... 48

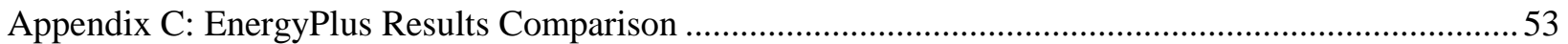




\section{LIST OF TABLES}

Table 1. The annual heat transfer crossing the attic floor and the annual energy losses for HVAC ducts contained in the attic.

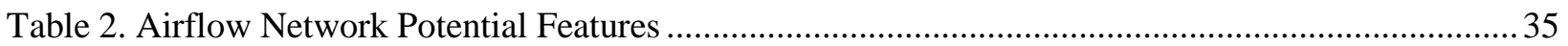

Table 3. Auxiliary File used to place boundary conditions from EnergyPlus on AtticSim simulations..... 44

Table 4. Detailed model comparison between AtticSim and EnergyPlus................................................ 48

Table 5. The three configurations of Airflow Network for comparison of EnergyPlus Results................. 53

Table 6. Comparison between EnergyPlus versions for Chicago ........................................................... 53

Table 7. Comparison between EnergyPlus versions for Atlanta.............................................................. 54 


\section{LIST OF FIGURES}

Figure 1. Comparison of energy impacts of $4 \%$ leaky ducts in an attic with a sealed floor versus $10 \%$, and $20 \%$ leaky ducts in attic space without a sealed floor, .......................................................... 11

Figure 2. Rendering of HERS BESTEST Case L100A building model.............................................. 13

Figure 3. Measured attic infiltration from tracer gas tests and improved AtticSim comparison for attic air change rates at field demonstration Charleston, South Carolina NET Facility. ....................... 14

Figure 4. Energy losses from an HVAC duct during winter operation for HERS BESTEST home simulated in Atlanta, GA.

Figure 5. Unwanted energy gains to an HVAC duct during summer operation for HERS BESTEST home simulated in Atlanta, GA.

Figure 6. Simple duct model for illustration of heat balance between supply and return ducts. ................ 17

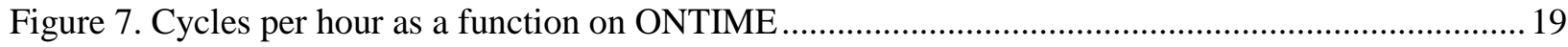

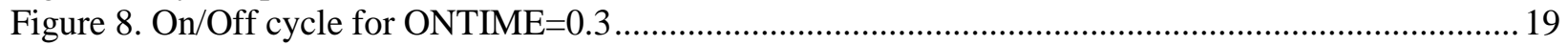

Figure 9. Actual ONTIME versus specified ONTIME (left) and percent error (right) ............................. 20

Figure 10. Modified method for calculating cycles per hour.................................................................... 20

Figure 11. Equation used for model growth factor ......................................................................... 21

Figure 12. Bulk air temperature change from the inlet to the exit of the test duct predicted by AtticSim (ordinate) and measured in the LSCS (abscissa).................................................................... 30

Figure 13. Attic air temperature computed by AtticSim/E+ and by EnergyPlus for the HERS BESTEST

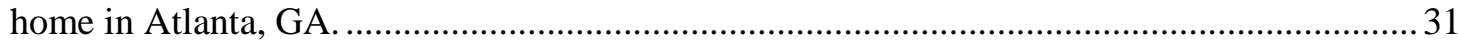

Figure 14. Attic air temperature and air exchange rate for AtticSim/E+ and EnergyPlus computed for Atlanta, GA climate. The attic contains a 10\% leaky duct. ................................................... 32

Figure 15. Attic air temperature and air exchange rate for AtticSim/E+ and EnergyPlus computed for Minneapolis, MN climate. The attic contains a 10\% leaky duct............................................... 33

Figure 16. Attic components for conventional roof without ASV ..................................................... 46

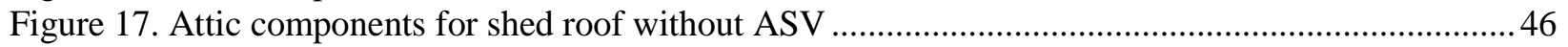

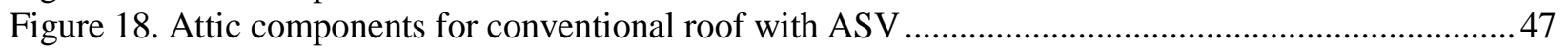

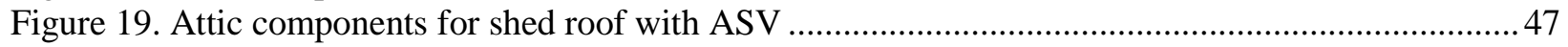




\begin{abstract}
Typically, the cheapest way to install a central air conditioning system in residential buildings is to place the ductwork in the attic. Energy losses due to duct-attic interactions can be great, but current wholehouse models are unable to capture the dynamic multi-mode physics of the interactions. The building industry is notoriously fragmented and unable to devote adequate research resources to solve this problem. Builders are going to continue to put ducts in the attic because floor space is too expensive to closet them within living space, and there are both construction and aesthetic issues with other approaches such as dropped ceilings. Thus, there is a substantial need to publicly document duct losses and the cost of energy used by ducts in attics so that practitioners, builders, homeowners and state and federal code officials can make informed decisions leading to changes in new construction and additional retrofit actions. Thus, the goal of this study is to conduct a comparison of AtticSim and EnergyPlus simulation algorithms to identify specific features for potential inclusion in EnergyPlus that would allow higherfidelity modeling of HVAC operation and duct transport of conditioned air. It is anticipated that the resulting analysis from these simulation tools will inform energy decisions relating to the role of ducts in future building energy codes and standards.
\end{abstract}

\title{
1 INTRODUCTION
}

Volume home builders learned long ago that, from a construction perspective, the most practical, cost effective place to put the HVAC box and ducts (herein, collectively "ducts") is in the attic. However, the typical attic is vented and unconditioned, providing a very harsh environment for ducts resulting in substantial energy loss. The attic is defined broadly to include the roof as well as the space between the roof and the finished ceiling below, which can include ducts for the heating, ventilating, and airconditioning (HVAC) system. Benefits of energy retrofits and strategies for roofs and attics depend on climate, attic geometry, duct arrangements, and other building parameters. However, ducts in an unconditioned space such as an attic often constitute the best return-on-investment by sealing the conditioned air so that it does not heat/cool the attic air.

Heat flows naturally from a warmer space to a colder space. Heat that flows into the building is called heat gain, while heat that flows out of the building is called heat loss. When too much heat gain or loss occurs, the building's air conditioning or heating system has to use more energy to keep the space comfortable. HVAC ducts distribute the conditioned air throughout the building. Since ducts are most often placed in the attic for residential buildings, duct leakage and conduction loss due to adverse environmental conditions cause a significant loss of energy. The capability of accurately simulating this effect has been historically limited due to the computational complexity of accurately capturing the geometry-dependent radiant heat transfer between an attic and the HVAC ducts.

The goal, therefore, is to analyze, assimilate and compare analytical methods used for predicting HVAC duct performance and to make recommendations for future work that will enhance the capabilities of simulation engines such as EnergyPlus.

\section{ATTIC MODELS}

Although there are many attic models, the present project focuses two attic models: AtticSim and EnergyPlus. This section provides a brief description of both models. 


\section{$2.1 \quad$ ATTICSIM}

AtticSim (version 12.6) is a computer tool for predicting the thermal performance of residential attics. It mathematically describes the conduction through the gables, eaves, roof deck and ceiling; the convection at the exterior and interior surfaces; the radiosity heat exchange between surfaces within the attic enclosure; the heat transfer to the ventilation air stream; and the latent heat effects due to sorption and desorption of moisture at the wood surfaces. Solar reflectance, thermal emittance and water vapor permeance of the sundry surfaces are input. The model can account for different insulation R-values and/or radiant barriers attached to the various attic surfaces. It also has an algorithm validated against laboratory data [1] that predicts the effect of air-conditioning ducts placed in the attic. The AtticSim code reads the roof pitch, length and width and the ridge orientation (azimuth angle with respect to north) and calculates the solar irradiance incident on the roof. Conduction heat transfer through the two roof decks, two gables and vertical eaves are modeled using the thermal response factor technique [2], which requires the thermal conductivity, specific heat, density and thickness of each attic section for calculating conduction transfer functions. Version 12.6 of AtticSim is structured to read the material property data for the seven attic surfaces and compute the response factors and conduction transfer functions (CTF) used in energy balances or the code can simply read in the CTFs as computed by codes independent of AtticSim.

Heat balances at the interior surfaces (facing the attic space) include the conduction, the radiation exchange with other surfaces, the convection and the latent load contributions. Heat balances at the exterior surfaces balance the heat conducted through the attic surface to the heat convected to the air, the heat radiated to the surroundings and the heat stored by the surface. Iterative solution of the simultaneous equations describing the heat balances yields the interior and exterior surface temperatures and the attic air temperature at one-hour time steps. The heat flows at the attic ceiling, roof sections, gables and eaves are calculated using the conduction transfer function equations. The tool was validated by [3] against field experiments, and is capable of predicting the ceiling heat flows integrated over time to within $10 \%$ of the field measurement. AtticSim can predict the thermal performance of attics having direct nailed roof products. It can also predict the heat flow across a tile roof or stone-coated metal roof having a venting occurring on the underside of the roof, between the roof deck and exterior roof cover [4].

A supply and return duct placed in the attic was modeled by AtticSim and by EnergyPlus. We used EnergyPlus to compute the run time for a 2-ton heat pump comfort conditioning the "HERS BESTEST" model home [5]. The heat pump was certified with a Seasonal Energy Efficiency Ratio (SEER) of 13. The "HERS BESTEST" model home [5] had an attic footprint of $1550 \mathrm{ft}^{2}\left(144 \mathrm{~m}^{2}\right)$. The roof slope was set at $18^{\circ}$ and a dark heat-absorbing shingle roof having solar reflectance of 0.10 was assumed for hot and cold climates using Typical Meterological Year (TMY2) [6] weather data. The AtticSim simulations assumed equal soffit and ridge vent openings with a net free vent area of 1:300' where ventilation area is defined as the ratio of the net free vent area to the footprint of the attic floor area.

\subsection{ATTIC MODEL IN ENERGYPLUS}

EnergyPlus treats an attic as a thermal zone. The zone air heat balance equation includes thermal mass storage, convective internal loads, heat transfer due to infiltration and ventilation, convective heat transfer from zone surfaces, and system output. The conduction transfer function is used to calculate heat transfer with given zone conditions at the previous time step. EnergyPlus uses the Airflow Network model to calculate duct losses.

\subsubsection{EnergyPlus’ Airflow Network (AFN) Description}

The Airflow Network model [7][8]provides the ability to simulate multizone airflows driven by wind and also by a forced air distribution system. The model can also simulate the heat and moisture gains or losses from the air distribution system itself (e.g., ductwork). When modeling an air distribution system, the 
current version of the Airflow Network model is restricted to a single forced air system with a constant volume or variable volume supply air fan. The capabilities of the model are to:

- Simulate zone pressures due to envelope leakage and forced air distribution during HVAC system fan operation

- Simulate node pressures in a forced air distribution system during HVAC system fan operation

- Calculate multizone airflows due to forced air, wind, and surface leakage, including adjacent zones and outdoors, during HVAC system fan operation

- Simulate distribution system airflows, including supply and return air leaks, during HVAC system fan operation

- Simulate air distribution system node temperatures and humidity ratios during HVAC system fan operation

- Calculate duct conduction losses during HVAC system fan operation

- Calculate vapor diffusion losses of ducts during HVAC system fan operation

- Calculate sensible and latent loads on the surrounding zones due to supply and return air leaks in the air distribution system during HVAC system fan operation

- Simulate zone pressures due to envelope leakage driven by wind when the HVAC system fan is off or if no air distribution system is specified

- Calculate multizone airflows due to wind and surface leakage, including adjacent zones and outdoors when the HVAC system fan is off or if no air distribution system is specified

- Allow zone exhaust fans to be included as part of the airflow network

- For airflow networks with a forced air distribution system, calculate zone sensible and latent loads for two different supply air fan operation modes as required: cycling fan, cycling compressor and continuous fan, cycling compressor.

\section{DUCTS PLACED IN UNCONDITIONED ZONES}

Conventional practices are often not the best choice for homeowners who want to save energy and lower their energy bills because many builders continue to install HVAC ducts in the attic, and the ducts are not well insulated or properly sealed to limit air leakage. Homeowners typically pay an added \$275 per year because of leaky and poorly insulated air conditioning ducts operating in a hot and leaky attic. Energy costs are also increased if the attic floor leaks air to or from the home. Duct location and sealing the attic floor are of paramount importance and should take precedence over other energy efficient roof and attic renovation and/or design. Figure 1 illustrates why these renovations should be a priority component of a building program, whether for retrofit work or for building a new home. 


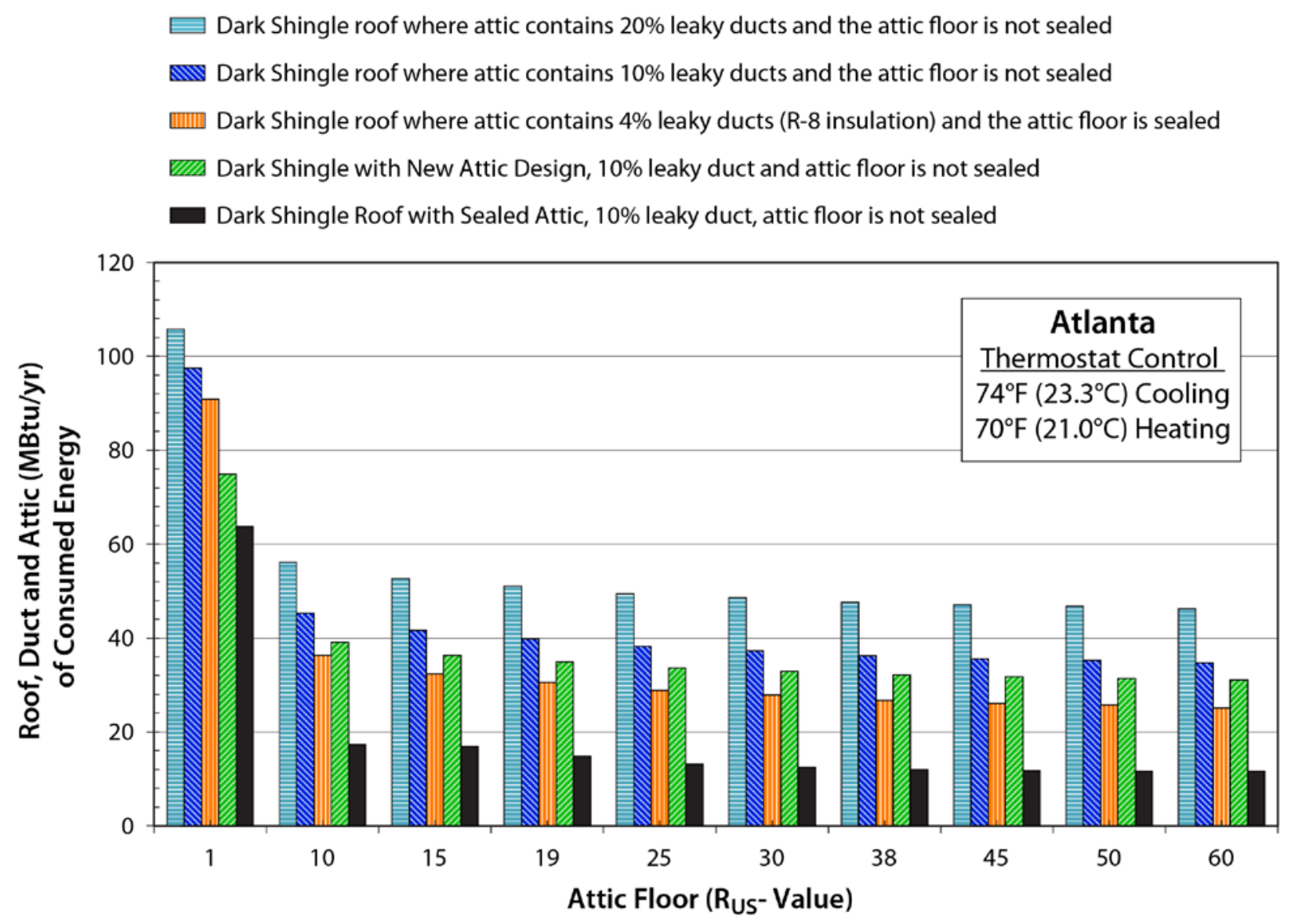

Figure 1. Comparison of energy impacts of $4 \%$ leaky ducts in an attic with a sealed floor versus $10 \%$, and $20 \%$ leaky ducts in attic space without a sealed floor,

The turquoise bars (horizontal crosshatching) and the darker blue bars (slanted crosshatching) represent energy use for a roof and attic where the roof is dark and the ducts are poorly insulated $\left(\mathrm{R}_{\mathrm{US}}{ }^{-5.5}\left(\mathrm{R}_{\mathrm{SI}^{-}}\right.\right.$ $0.96)$ and leaky (20\% and $10 \%$ respectively). The orange bars show energy use where the practitioner repaired the leaks in the attic and rewrapped the ducts in $\mathrm{R}_{U S}-8\left(\mathrm{R}_{\mathrm{SI}^{-}} 1.4\right)$ insulation where $\mathrm{R}_{\mathrm{US}}-8$ $\left(\mathrm{hr} \cdot \mathrm{ft}^{2} \cdot{ }^{\circ} \mathrm{F}\right)$ per Btu $\left[\mathrm{R}_{\mathrm{SI}^{-}}-1.4\left(\mathrm{~m}^{2} \cdot{ }^{\circ} \mathrm{C}\right)\right.$ per $\left.\left.\mathrm{W}\right)\right]$. The light green bars are for a new-design roof [9] that exploits the use of radiation, convection and insulation controls to reduce its peak day heat transfer by almost 85 percent of the heat transfer crossing a conventional roof and attic assembly. The attic assembly, however, has ductwork that leaks $10 \%$ of the supply air on the supply side and return side of the HVAC. The black bars represent a renovated attic where the homeowner had the $10 \%$ leaky ducts and the attic transformed into a semi-conditioned space by sealing the attic.

Adding insulation reduces your energy bill for all cases simulated in Atlanta as seen in Figure 1. However, the energy savings achieved with more insulation does not counterbalance the energy lost by the ducts. Sealing all duct joints with mastic and wrapping the ducts with $\mathrm{R}_{U \mathrm{US}}-8\left(\mathrm{R}_{\mathrm{SI}}-1.4\right)$ insulation drops the energy losses through ducts in the attic by roughly $40 \%$ (Figure 1, turquoise or dark blue bars compared to orange bars). An attic with $\mathrm{R}_{\mathrm{US}}-60$ ( $\left.\mathrm{R}_{\mathrm{SI}}-10.6\right)$ floor insulation but with leaky ducts and leaky floor (Figure 1, dark blue bar) has greater heat energy losses than an attic with just $R_{U S}-10$ ( $\left.R_{S I}-1.76\right)$ floor insulation but with $4 \%$ leaky ducts (Figure 1, orange bar). In many homes, the ductwork increases airconditioner energy use by roughly $18 \%$ for moderately leaky ducts in a well-insulated attic [10][11]. 
After some repair to the ducts (20\% leak dropped to 10\%), sealing the attic floor, and adding insulation, what's next? Installing a new roof design (light green bars, Figure 1) will recoup about \$200 of that \$275 lost by the ducts and leaky attic. However, because of the magnitude of duct losses, the new roof designs do not fully compensate for the inefficiency of the ducts if floor insulation exceeds $R_{U S}-10\left(R_{S I}-1.8\right)$. Therefore, the recommendation is to always install HVAC ducts in the conditioned space of the residence rather than in the unconditioned attic. Making the attic into a semi-conditioned space is a viable option because the ducts are used to create their own conditioned space with air leakage that is otherwise lost to the environment (Figure 1,, black bars). Therefore, moving the ductwork from the attic to the conditioned space or making the attic into a semi-conditioned space halves the roof and attic energy as compared to having leaky ducts in the attic. The results show the importance of duct losses when operating in the extreme temperatures of the attic and the importance of accurately predicting losses in order to make energy and economic decisions regarding energy policy.

\section{COMPARISON OF DUCT MODELS}

\subsection{BUILDING MODEL}

The Home Energy Rating System Building Energy Simulation Test (HERS BESTEST) Case L100A building model [5], shown in Figure 2, was used as a base building for this study. The building is a $57 \mathrm{ft} \times$ $27 \mathrm{ft}$ single-story house with one conditioned zone, an unconditioned attic, and a vented crawl space. Although many of the homes in the southern climates are built on slabs, the crawl space foundation was retained in all zones for consistency. Because the temperature within the conditioned zone is considered to be well-mixed (i.e., no stratification), and is controlled to a setpoint, the air temperature below the attic floor (produced by EnergyPlus and used by AtticSim) should be unaffected by the foundation type. The foundation type would have a slight impact on the total house load, which would in turn impact the timing of the air entering the ductwork (the other EnergyPlus output used by the AtticSim model), but this should be a secondary effect, at worst. An hourly internal load schedule for the conditioned zone was also used as per the HERS BESTEST Case L100A building. For all climate zones, an interior $68^{\circ} \mathrm{F}$ heating set point temperature and $78^{\circ} \mathrm{F}$ cooling set point temperature were used. The supply and return ducts were assumed to have $10 \%$ leakage.

Airflow Network module in EnergyPlus was used to model the supply and return duct systems in an attic. In the Airflow Network module, the duct air leak for each moment in time is a function of four characteristic parameters ("Effective Leakage Ratio", "Maximum Flow Rate", "Reference Pressure Difference", and "Air Mass Flow Exponent”) and two weather parameters (wind velocity and direction). The "Effective Leakage Ratio" was adjusted to get approximately the same duct air leakage rate, as a fraction of the total duct flow rate, for all climate zones. 


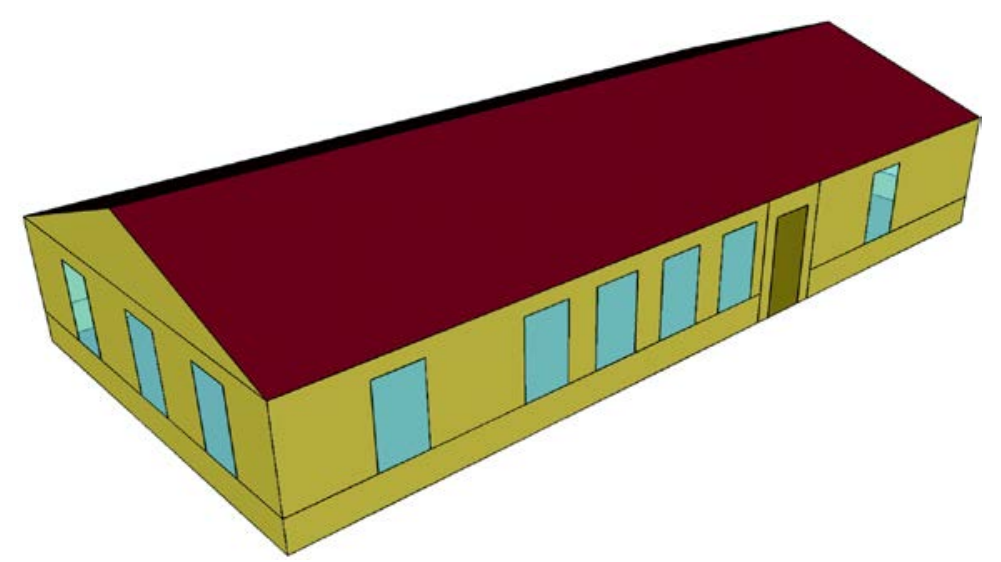

Figure 2. Rendering of HERS BESTEST Case L100A building model

AtticSim read an auxiliary file generated by EnergyPlus that included the hourly indoor air temperature for the house, the run time for the HVAC, the flow rate of air in the ducts and the duct supply air temperature. AtticSim made simulations with the EnergyPlus generated boundary conditions to directly compare the duct losses computed by EnergyPlus to that computed by AtticSim. Therefore a modified AtticSim, termed herein as AtticSim/E+, was compared to results for EnergyPlus. Two different leakage rates for the supply and return ducts were modeled; (Case 1) sealed duct having no air leakage and (Case 2) supply and return ducts having $10 \%$ leakage. For Case 1 with no duct leakage, the attic's soffit-to-ridge ventilation was also made the same between AtticSim and EnergyPlus to hopefully remove confounding issues with internal convection heat transfer. For Case 2 with duct leakage, we let both codes compute attic air exchange to view the combined effect of convection and radiation internal to the attic.

\subsection{ATTIC PHYSICS}

\subsubsection{Convection}

Attic ventilation is an important issue for the study because it affects the heat flow crossing the attic floor and the energy gains and losses for the ducts. Numerical experiments were carried out using COMSOL, a computational fluid dynamics (CFD) computer program, on the two roof types modeled by AtticSim: (1) conventional roofs where the roof slope is the same on both sides of the ridge and (2) shed roofs where one side is sloped and the other side is vertical. Results were examined and an algorithm formulated which accounts for wind speed, wind direction, roof slope, building width and the soffit and ridge vent areas. The algorithm was validated against field measures collected from the Charleston Natural Exposure Test (NET) facility obtained with the tracer gas technique as shown in Figure 3. 


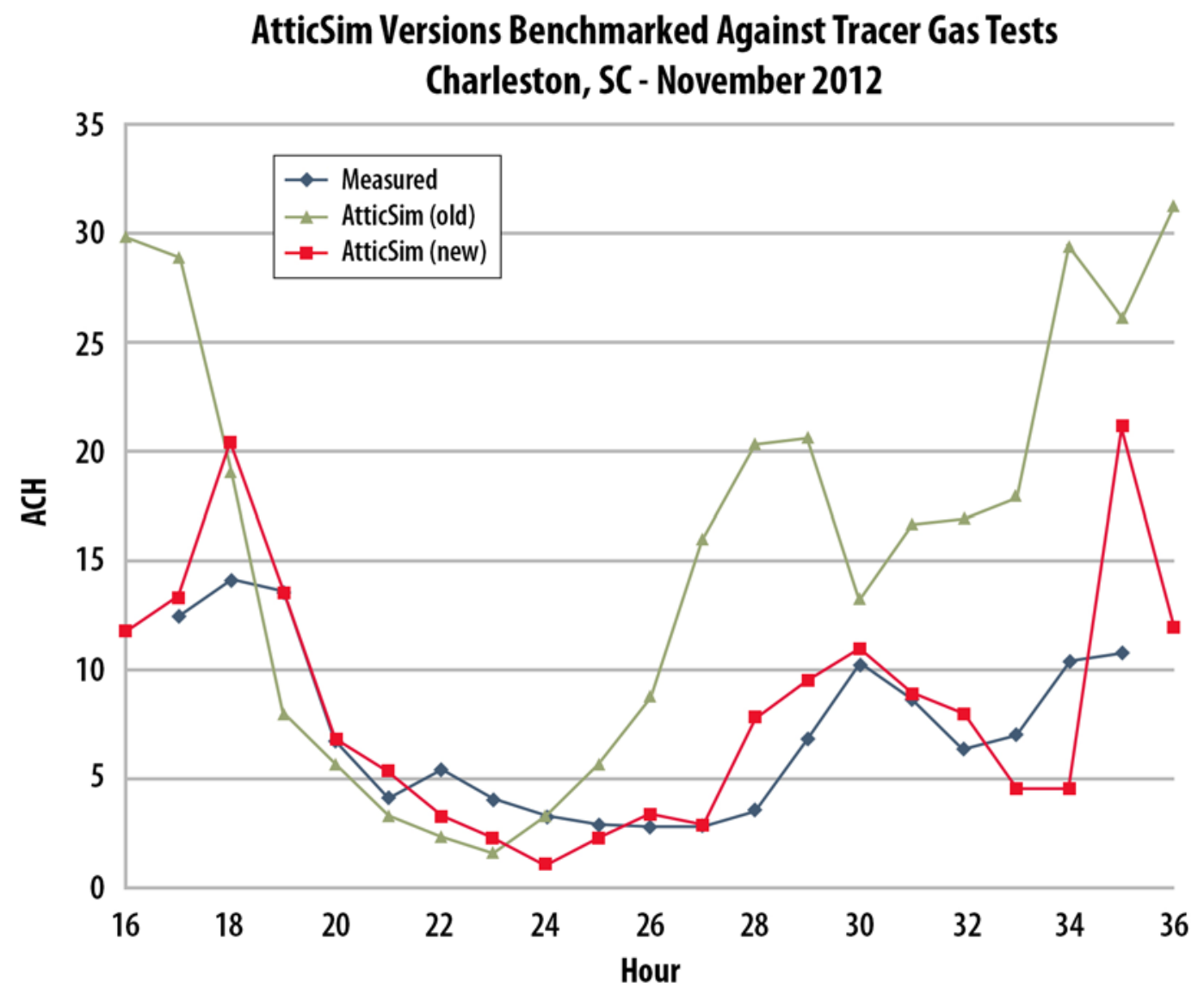

Figure 3. Measured attic infiltration from tracer gas tests and improved AtticSim comparison for attic air change rates at field demonstration Charleston, South Carolina NET Facility.

The older attic ventilation model (version 9.0) and the newer version (version 12.6) are compared to data for a period in November 2012. The AtticSim calculation is driven by weather data measured at the NET facility. The comparison is presented in Figure 3. The predicted air exchange rate for the new wind-driven attic ventilation algorithm in AtticSim is a better match to the measured data than with the old algorithm. The new algorithm produces a good match to the measured air change rate except when air exchange rate is fairly high (over 15 air changes per hour predicted by AtticSim). The tracer gas technique being used is known to be unreliable at high air exchange rates and it represents the average rate over a much shorter time than the one hour time used by AtticSim.

\subsubsection{Radiation}

AtticSim was exercised to observe the effects of convection, radiation, thermal capacitance and air leakage on duct losses in an unconditioned attic. Petrie [1] validated the duct algorithm against laboratory measures acquired from ORNL's Large Scale Climate Simulator (LSCS) to show that the algorithm predicts the effect of air-conditioning ducts placed in the attic. To the authors' knowledge Petrie's data is unique and has not been duplicated in any other study.

Simulation results for Atlanta are presented for 3 contiguous winter days (Figure 4) and for 3 contiguous summer days (Figure 5). Simulations show the leakage of $10 \%$ of the supply and $10 \%$ of the return air as 
the predominant loss from the duct during winter operation. The attic air temperatures ranged from about 30 to $65^{\circ} \mathrm{F}$ ( -1 to $18^{\circ} \mathrm{C}$ ). Radiation and convection from the duct show similar energy losses and at peak day irradiance these losses are each at best $15 \%$ of the total duct loss. The duct was modeled as made of 26 gage steel and the gains and losses in thermal capacitance is computed from the difference in wall temperature as function of the time the unit is on or off. As example, in Figure 4 at just before noon of the $2^{\text {nd }}$ contiguous day the HVAC unit cycles off. The sheet metal is warm because it has been supplying warm conditioned air and as the duct cools in the cold attic at about $35^{\circ} \mathrm{F}\left(1.7^{\circ} \mathrm{C}\right)$ it loses heat, Figure 4 . Similarly when the unit energizes the duct material gains some heat from the supply air and there is an energy gain to the duct.

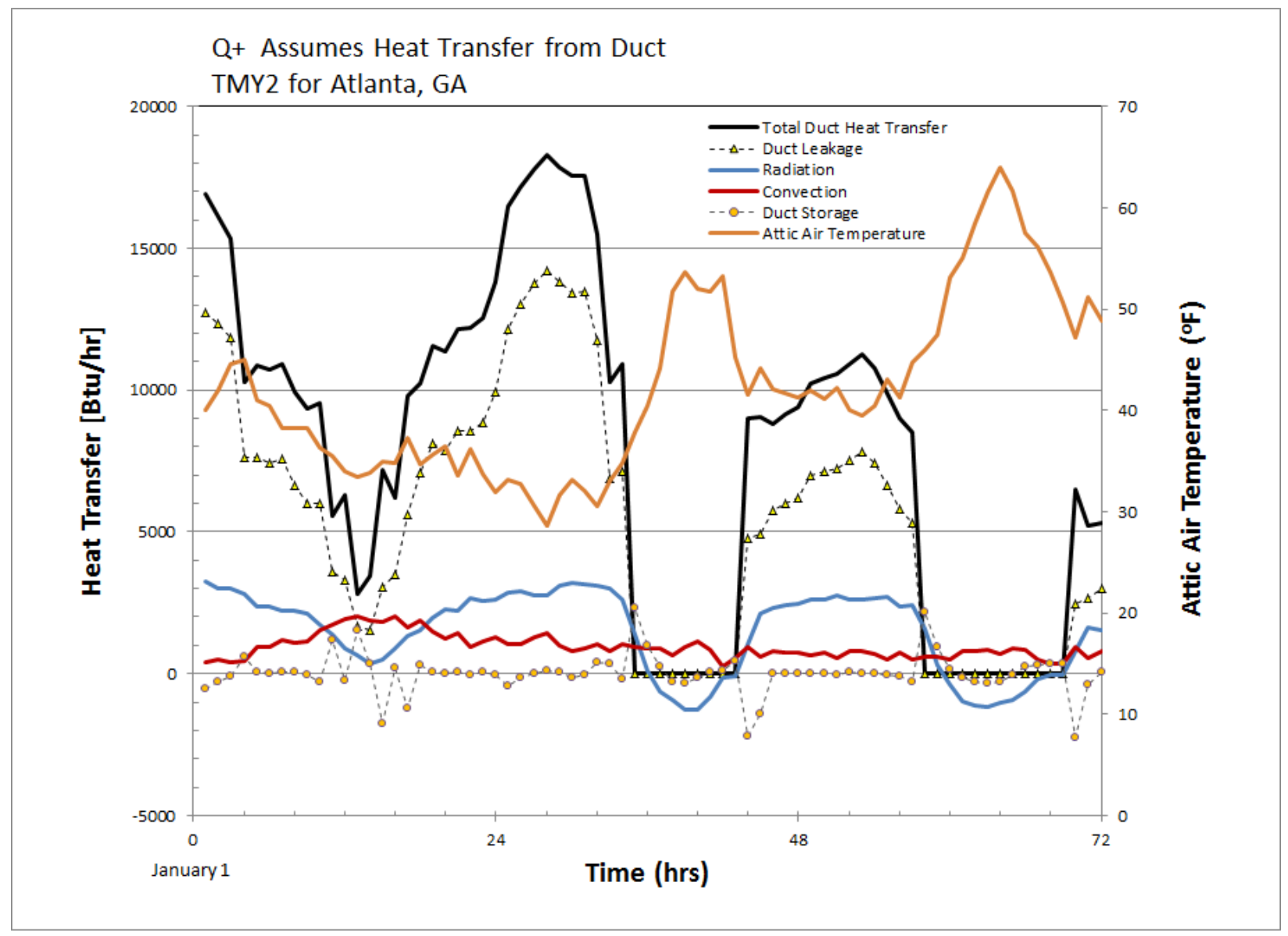

Figure 4. Energy losses from an HVAC duct during winter operation for HERS BESTEST home simulated in Atlanta, GA.

Summer simulation revealed very interesting yet different trends from those observed for winter, Figure 5. During the summer, the radiation heat transfer gain to the ducts from the seven attic surfaces is about the same as the gains due to air leakage. Radiation peaks around solar noon for the 3 consecutive days as does the losses due to air leakage. Therefore radiation is more predominant in summer than in winter, while duct leakage is prevalent all year. It is also very interesting that the convection heat transfer shows a loss from the duct whereas radiation and leakage show gains. The duct contains cold conditioned air but the exterior of the duct is being heated by radiation to the point that convection heat transfer is from the 
duct insulation to the attic air. This implies that the exterior temperature of the insulated duct $\left[\mathrm{R}_{\mathrm{Us}}-8\left(\mathrm{R}_{\mathrm{SI}}{ }^{-}\right.\right.$ 1.4)] is warmer than the attic air temperature as caused by radiation heat transfer. The attic air temperature peaks at about 88 to $95^{\circ} \mathrm{F}\left(31\right.$ to $35^{\circ} \mathrm{C}$ ) for these 3 consecutive days. Hence simulation models need to account for the radiation heat transfer from the attic surfaces to the ducts for developing more accurate estimates of whole house performance.

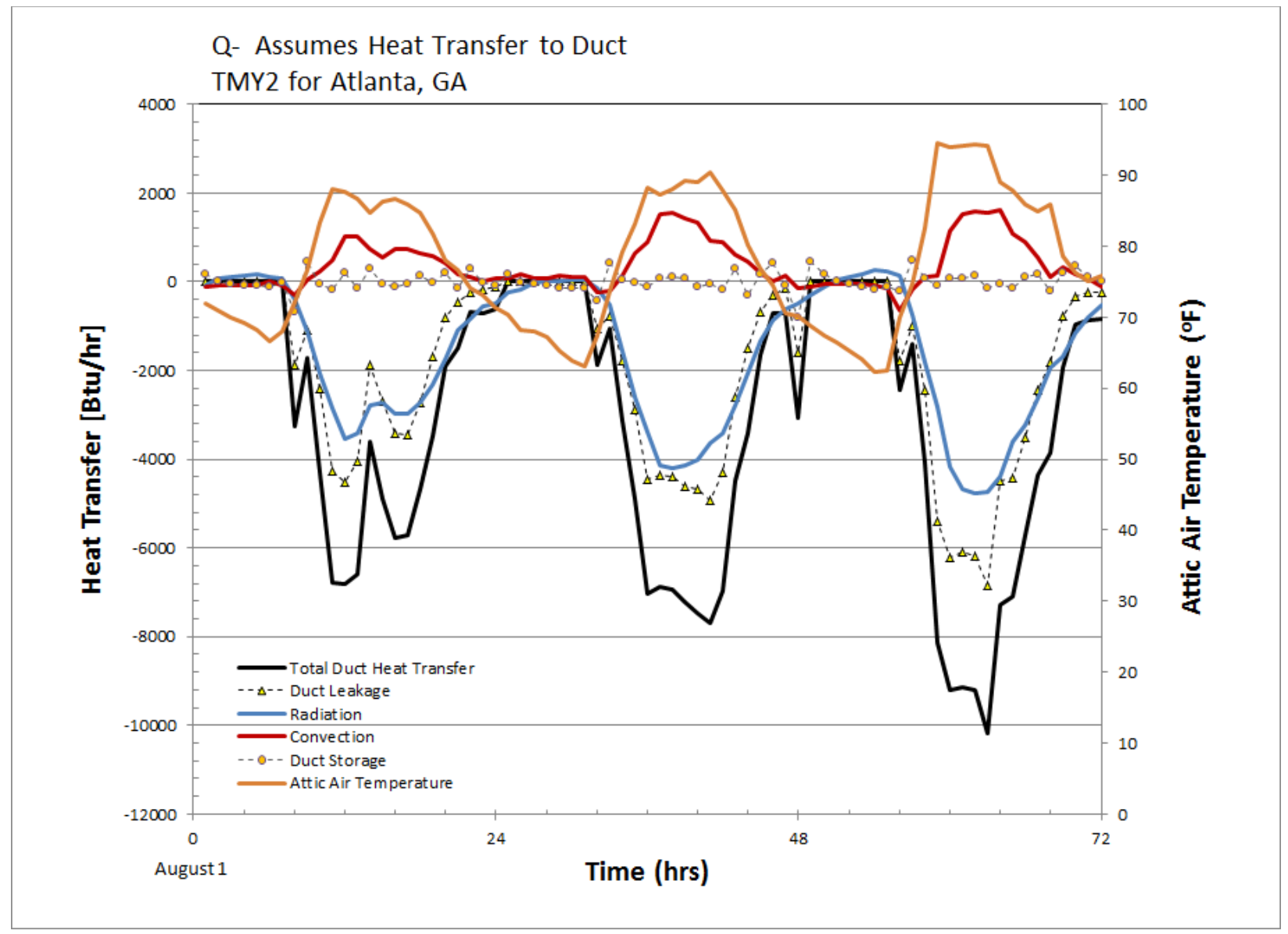

Figure 5. Unwanted energy gains to an HVAC duct during summer operation for HERS BESTEST home simulated in Atlanta, GA.

\subsection{DUCT SIMULATIONS}

\subsubsection{AtticSim}

The attic simulator, AtticSim, was developed to calculate the radiative, convective, and conductive energy exchanges in specific attic geometry, with or without ducts [3][12]. This model has been benchmarked against experimental data from the controlled laboratory experiments, showing excellent accuracy for attics without ducts and moderate accuracy for attics with ducts [1]. The attic model requires one to specify the air temperature below the attic floor as well as the temperature and timing of air entering the ductwork. To provide these values, a whole-building energy model was developed in EnergyPlus. This whole-building model includes duct air leakage, duct heat loss (convection and conduction), and radiation 
energy exchange within the attic, but does not yet include radiant exchange between the attic surfaces and the duct surface. Input parameters for AtticSim, such as, the conditioned space air temperature and air temperature and flow rate entering the supply and return ducts were from EnergyPlus simulation result. Identical attic structure (geometry and materials), duct details (size, length, leakage rate), and weather data was used in AtticSim and EnergyPlus simulations.

Several modifications have been made to the AtticSim code which are partially but not completely captured in the AtticSim Subversion source control repository. The starting point for these modifications was the Fortran 90 version of the code created by Kaushik Biswas.

\subsubsection{Correction to HVAC Loads due to Ducts}

A parametric study was performed with AtticSim in an effort to determine the impact of leaky supply and return ducts on the HVAC load. In this study three leaky-duct scenarios were examined: (1) leaks in supply ducts only, (2) leaks in return ducts only and (3) leaks in both supply and return ducts. The results indicated that when both supply and return ducts leaked the HVAC load was smaller than if there were leaks only in supply ducts or only in return ducts. Since this is physically incorrect, a closer examination of the code was undertaken. At each time step, AtticSim marches along the length of each duct doing detailed energy balances to determine the temperature of the air exiting the duct. The instantaneous load due to the ducts is then calculated as

$$
\dot{Q}_{\text {ducts }}=\sum_{i=1}^{N_{\text {ducts }}}\left(\dot{m}_{\text {in }} c_{p} T_{\text {in }}-\dot{m}_{\text {out }} c_{p} T_{\text {out }}\right)_{i}
$$

If there is no leakage from the ducts, Equation 1 is the load placed on the HVAC system due to the ducts. A positive value indicates energy loss from the ducts or a heating load. However, if there is leakage from a duct, this equation does not give the load due to the ducts. To illustrate this, consider a simple case with a leaky supply duct and a non-leaky return duct as shown in Figure 6.

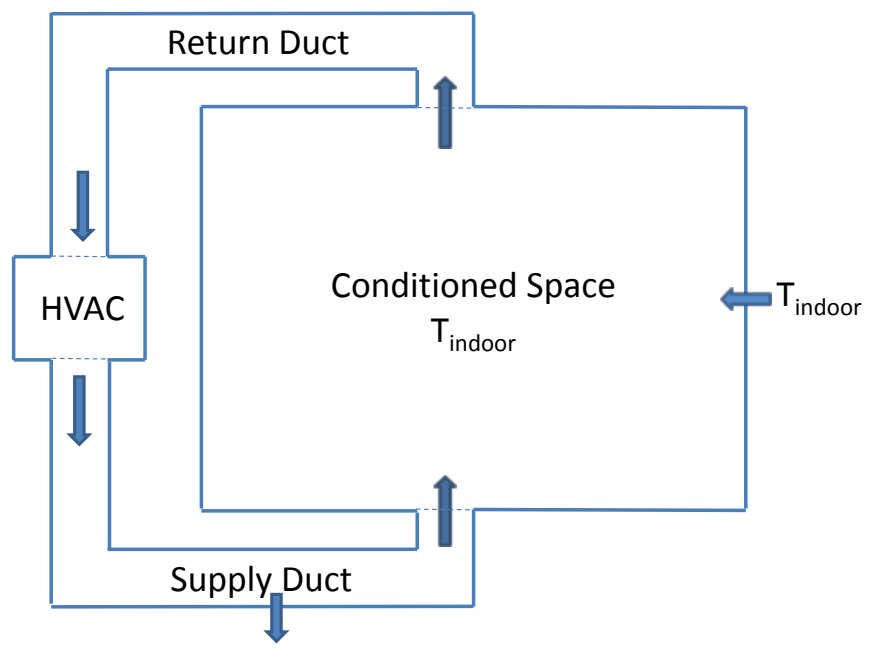

Figure 6. Simple duct model for illustration of heat balance between supply and return ducts.

While equation 1 still gives the energy change between inlet and outlet air streams (which includes heat transfer between the duct and the air stream and the energy contained in the air that leaks from the duct), 
this is not the load placed on the HVAC system. For illustrative purposes if we further simplify the problem by assuming that the supply duct is perfectly insulated then $T_{\text {out }}$ equals $T_{\text {in }}$ and Equation 1 gives

$$
\dot{Q}_{\text {supplyduct }}=\left(\dot{m}_{\text {in }}-\dot{m}_{\text {out }}\right) c_{p} T_{\text {in }}=\dot{m}_{\text {leak }} c_{p} T_{\text {in }}
$$

Equation 2 implies that leakage from a supply duct always represents a loss of energy (or a heating load) regardless of the outdoor temperature - which is not correct. What is not being taken into consideration in AtticSim is that a mass of air equal to the supply duct leakage must be reintroduced to the conditioned space from somewhere. In this case, since more air is leaving the conditioned space through the return duct than is being supplied to the space from the supply duct, outdoor air has to be drawn into the conditioned space to make up the difference. There is an inherent assumption in AtticSim that there is no net mass gain or loss from the ducts. The calculation of the HVAC load due to ducts is only correct if there are no leaks in the ducts or if the mass flow rate leaking from the supply ducts exactly matched the mass flow rate leaking into the return ducts. To correct for this in AtticSim any net mass gain or loss in the conditioned space created by leaks in the duct system has to be compensated. If leaks from the supply ducts exceed leaks into the return ducts then air is drawn into the conditioned space from the outdoors to make up the net difference.

$$
\dot{Q}_{\text {ducts }}=\sum_{i=1}^{N_{\text {ducts }}}\left(\dot{m}_{\text {in }} c_{p} T_{\text {in }}-\dot{m}_{\text {out }} c_{p} T_{\text {out }}\right)_{i}+\dot{m}_{\text {net }} c_{p} T_{\text {outdoor }}
$$

If leaks into the return ducts exceed leaks from the supply ducts then indoor air has to exhausted from the conditioned space to make up the net difference.

$$
\dot{Q}_{\text {ducts }}=\sum_{i=1}^{N_{\text {ducts }}}\left(\dot{m}_{\text {in }} c_{p} T_{\text {in }}-\dot{m}_{\text {out }} c_{p} T_{\text {out }}\right)_{i}-\dot{m}_{\text {net }} c_{p} T_{\text {indoor }}
$$

\subsubsection{Correction to HVAC "On Time" Fraction}

When AtticSim calls the transient duct subroutine (DUCTTR) to calculate performance for an hour it supplies a variable (ONTIME) giving the fraction of time during the hour that the HVAC system is on. AtticSim calculates the number of cycles per hour using Equation 5. A plot of the number of cycles per hour versus the specified on time is shown in Figure 8.

$$
N_{\text {cycles }}=3 * 4 * \text { ONTIME* }(1-\text { ONTIME })
$$

The time that the HVAC is on during a cycle is given by Equations 6, and the time that it is off is given by Equation 7 .

$$
\begin{aligned}
& t_{\text {on }}=\text { ONTIME } / N_{\text {cycles }} \\
& t_{\text {off }}=(1-\text { ONTIME }) / N_{\text {cycles }}
\end{aligned}
$$




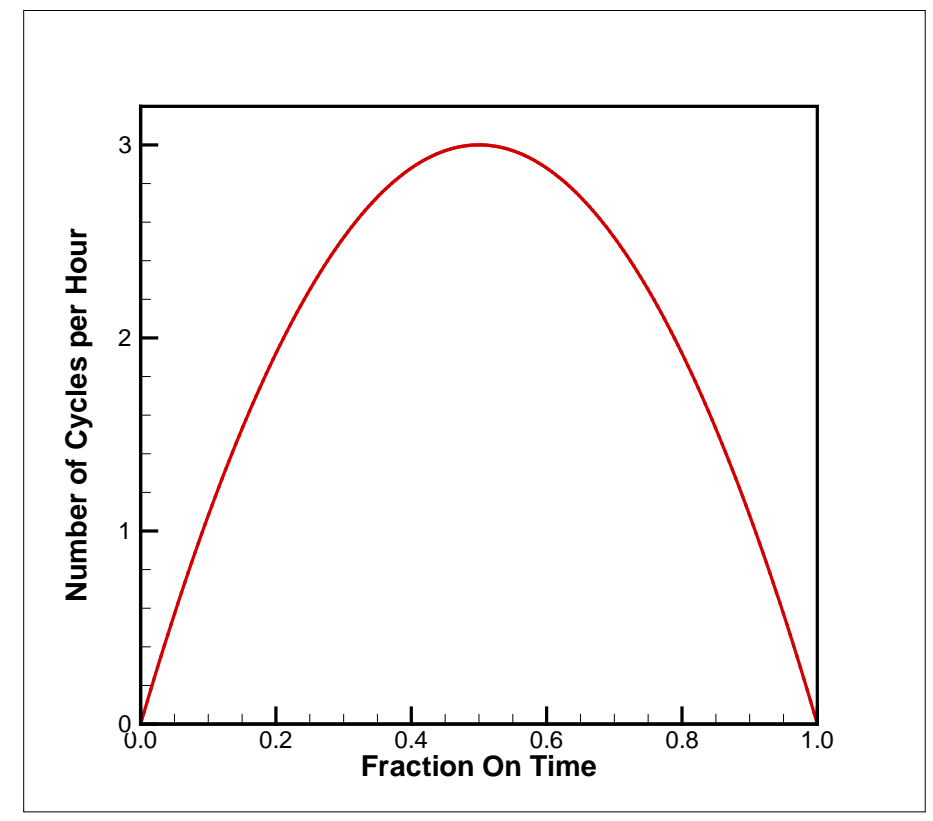

Figure 7. Cycles per hour as a function on ONTIME

During the calculation for an hour AtticSim begins with the HVAC on for time $t_{\text {on }}$ and then turns it off for time $t_{\text {off }}$. This on/off cycle is repeated until the end of the hour is reached. Unfortunately, this procedure does not guarantee that the specified on time is achieved for the hour. The problem can be illustrated with a simple example. If ONTIME is specified to be 0.3 then $N_{\text {cycles }}=2.52, t_{\text {on }}=0.119$ hours and $t_{\text {off }}=0.278$ hours. Figure 8 shows a plot of the on/off cycles for an hour. Since the third cycle was not completed during the hour the fraction of time the HVAC ran during the hour is greater than the specified ONTIME. Figure 9 shows a plot of actual ONTIME versus specified ONTIME (left) and percent error (right).

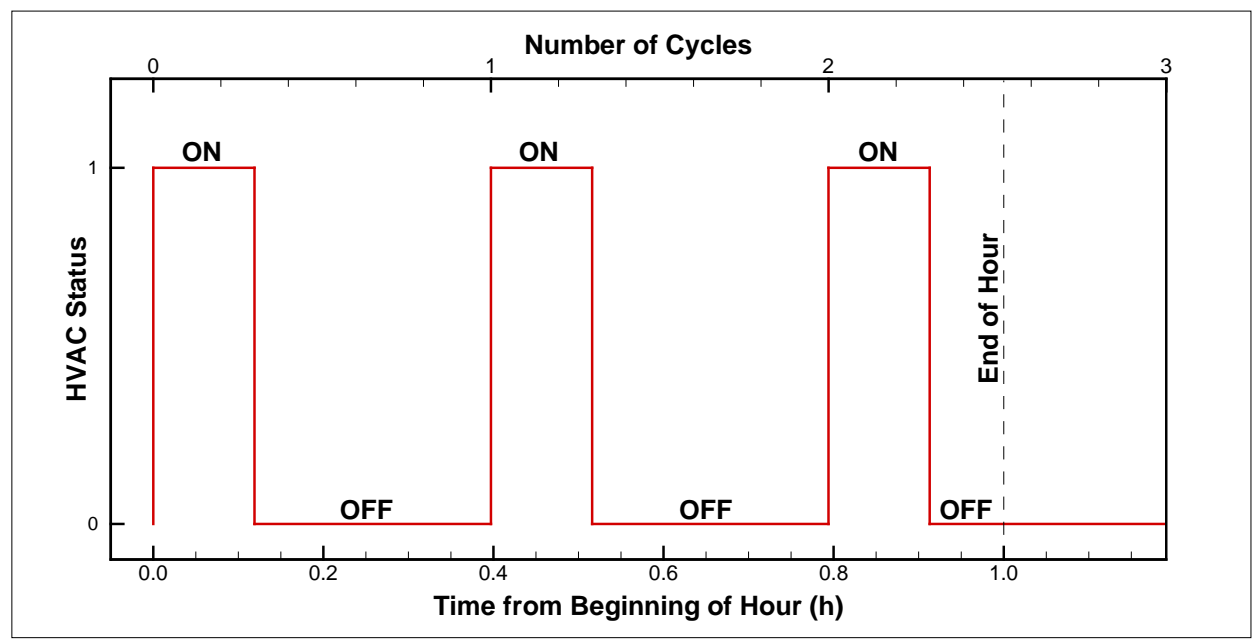

Figure 8. On/Off cycle for ONTIME=0.3 

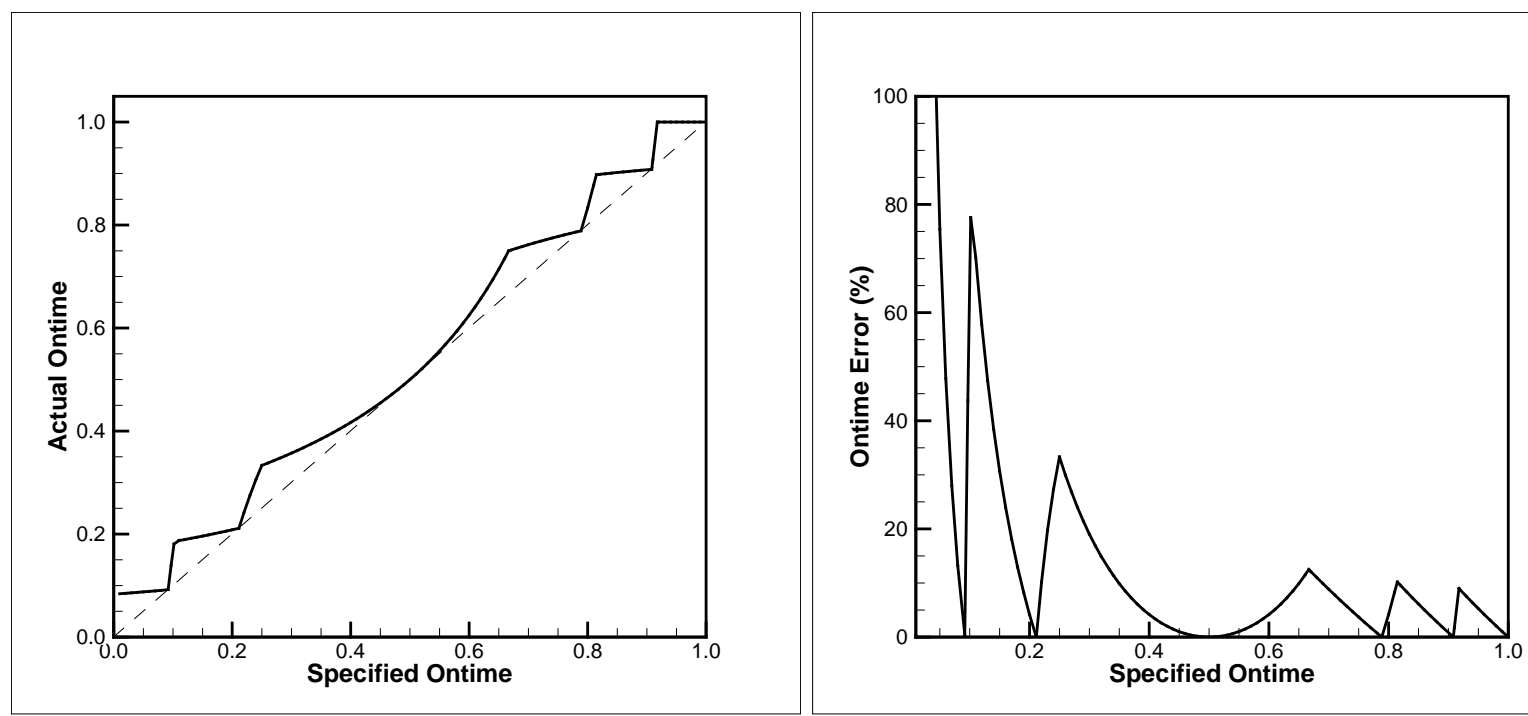

Figure 9. Actual ONTIME versus specified ONTIME (left) and percent error (right)

To correct this discrepancy in specified and achieved ONTIME, AtticSim was modified to always have an integer number of cycles per hour as illustrated in Figure 10.

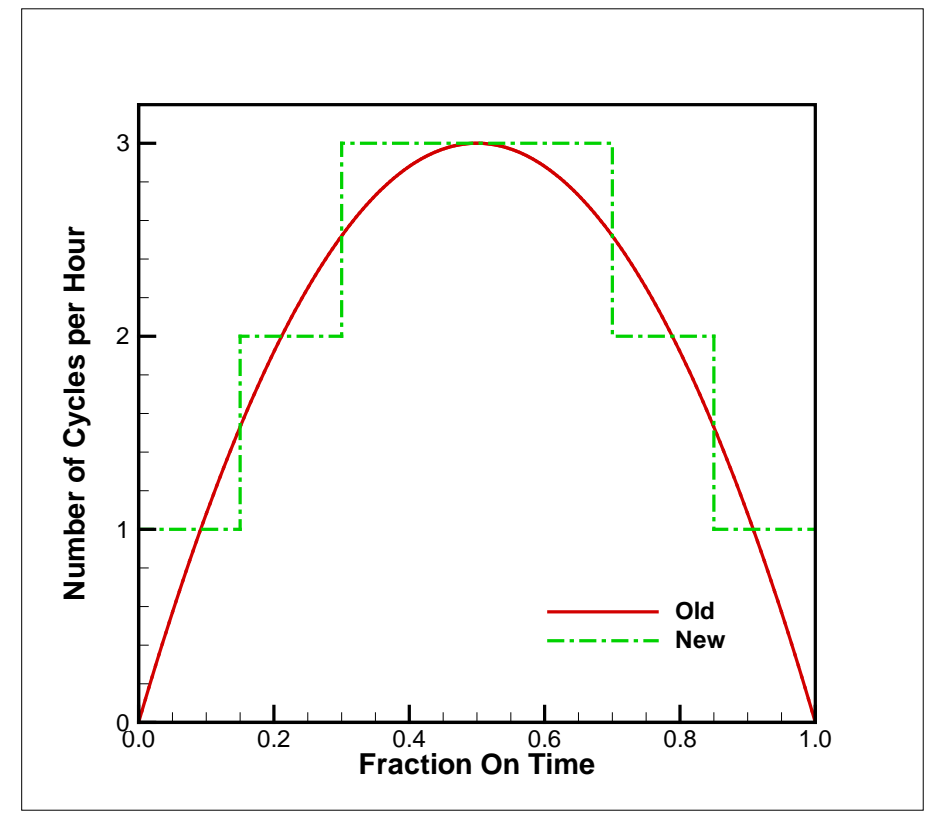

Figure 10. Modified method for calculating cycles per hour

\subsubsection{Change in Duct Length for Large Buildings}

When performing its energy balance calculation on a duct AtticSim divides the duct length into a number of equal-length segments. Each segment has a maximum length of 1 foot, and there are a maximum of 
100 segments. Thus the maximum length for any duct is 100 feet. However, commercial buildings commonly have duct runs much greater than 100 feet in length, so there is a need to remove this restriction from AtticSim. There are two very simple approaches to handle longer ducts: (1) keep the 1 foot segment length but increase the number of segments or (2) keep a maximum of 100 but increase the segment length. Both of these approaches have shortcomings. Increasing the number of segments will drastically increase the time required to run a simulation. Increasing the segment length can introduce inaccuracies in the calculations - particularly near the duct entrance where temperatures may be changing rapidly along the duct length. Thus, a third hybrid approach was implemented where the segment length is 1 foot at the duct entrance but each segment along the duct is progressively longer than the previous segment. This allows the code to handle the rapidly changing condition near the entrance, while limiting the number of segments by having longer segments further down the duct where change is much more gradual. Figure 11 shows the required growth factor to obtain the desired duct length using 100 segments. Also shown in the figure is the equation used by AtticSim to calculate the growth factor. The equation was obtained by curve fit using the commercial software package TableCurve 2D. This modification was tested by comparing results from a version of AtticSim where the number of 1-foot segments was increase to give the desired length to a version with 100 segments with increasing length down the duct. For the cases tested, the two versions gave essentially the same results for duct lengths up to 1000 feet, but the case with 100 increasing-length segments runs much faster.

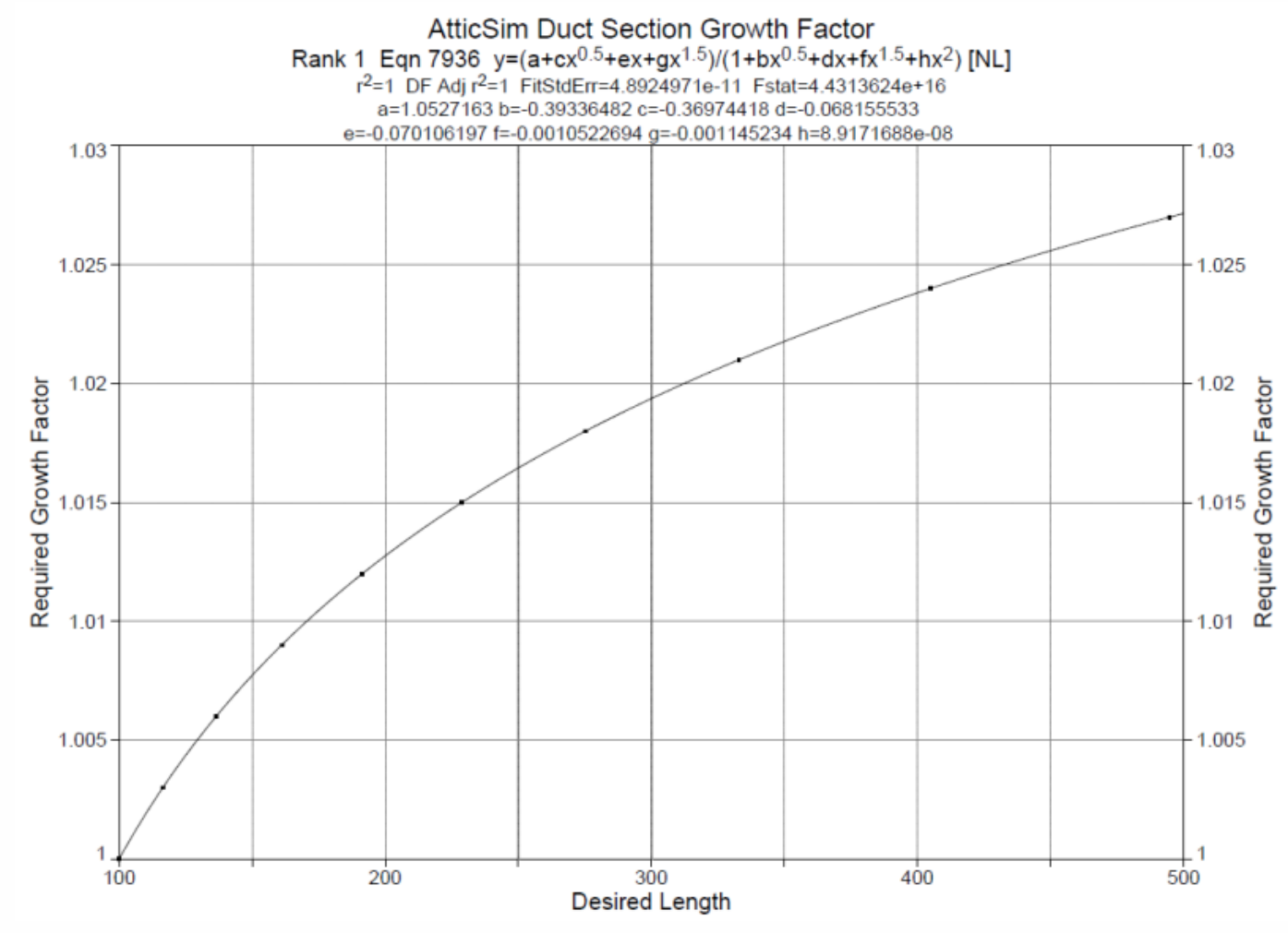

Figure 11. Equation used for model growth factor

\subsubsection{Longer Time Step to Speed Up Execution}

Since there is a desire to speed up execution of AtticSim, the code was examined to determine if there were any simple changes that might help accomplish this. An obvious place to look is the time step used. 
AtticSim uses a time step of 20 seconds which seems smaller than might be required to get good results. Therefore the time step was varied in a series of test runs to see how large it could be without adversely impacting the results. When using a fixed time step there can be a problem with obtaining the desired on time during an hour since the end of a time step probably will not hit the exact time the HVAC is to be turned on or off. In fact the actual on time can be off as much as one time step in either direction for each cycle. This may have been part of the motivation behind the 20 second time step used. To avoid this problem when going to larger time steps, the time step was adjusted slightly so that there were always an integer number of time steps during the on portion of the cycle. A similar adjustment was made to the time step for the off portion of the cycle. This means that the time steps for the on and off portions of the cycle are slightly different, but the desired on time will always be achieved. Time steps up to 4 minutes were examined. It was concluded that a time step of 2 minutes could be used without adversely impacting the results. A two-minute time step resulted in a code speedup by a factor of 3 to 5 depending on the case being run.

\subsubsection{Airflow Network}

The Airflow Network model in EnergyPlus [7] calculates nodal pressures and linkage airflows first, using the zone conditions at the previous time step, outdoor conditions and supply fan airflow rate. Then, nodal temperature and humidity ratio calculations are performed, using the coil conditions. Duct losses from conduction and leakage are calculated based on airflow rates and nodal conditions, as a part of system load, in addition to zone loads, so that the setpoint in the controlled zones will be achieved.

\subsubsection{Pressure and Airflow Calculations}

The EnergyPlus Airflow Network consists of a set of nodes linked by airflow components. Therefore, it is a simplified airflow model, compared to detailed models such as those used in computational fluid dynamics (CFD) models. The node variable is pressure and the linkage variable is airflow rate. A detailed description of the airflow network model may be found in [13][14][15].

\subsubsection{Node Temperature Calculations}

A brief description of the air node temperature calculation is given below. A detailed description can be found in [16]. The following equation is used to calculate temperature distribution across a duct element at the given airflow rate and inlet air temperature:

$$
\dot{m} C_{p} \frac{d T}{d x}=U P\left(T_{\infty}-T\right)
$$

where

$C_{p} \quad=$ Specific heat of airflow $[\mathrm{J} / \mathrm{kg} \cdot \mathrm{K}]$

$\dot{m} \quad$ = Airflow rate $[\mathrm{kg} / \mathrm{s}]$

$P \quad=$ Perimeter of a duct element [m]

$T=$ Temperature as a field variable $\left[{ }^{\circ} \mathrm{C}\right]$

$T_{\infty} \quad=$ Temperature of air surrounding the duct element $\left[{ }^{\circ} \mathrm{C}\right]$

$U \quad=$ Overall heat transfer coefficient $\left[\mathrm{W} / \mathrm{m}^{2} \cdot \mathrm{K}\right]$ 


$$
U=\frac{1}{\frac{1}{h_{i}}+\frac{1}{h_{o}}+\sum \frac{t_{j}}{k_{j}}}
$$

$h_{i}=$ Inside heat transfer coefficient $\left[\mathrm{W} / \mathrm{m}^{2} \cdot \mathrm{K}\right]$

$h_{o}=$ Outside heat transfer coefficient $\left[\mathrm{W} / \mathrm{m}^{2} \cdot \mathrm{K}\right]$

$t_{j}=$ Thickness at $\mathrm{j}$-th layer $[\mathrm{m}]$

$k_{j}=$ Thermal conductivity at $\mathrm{j}$-th layer $[\mathrm{W} / \mathrm{m} \bullet \mathrm{K}]$

The outlet air temperature at the end of the duct $(x=L)$ is:

$$
T_{o}=T_{\infty}+\left(T_{i}-T_{\infty}\right) * \exp \left(-\frac{U A}{m \dot{C}_{p}}\right)
$$

where

$$
\begin{array}{ll}
T_{i} & =\text { Inlet air temperature }\left[{ }^{\circ} \mathrm{C}\right] \\
T_{o} & =\text { Outlet air temperature }\left[{ }^{\circ} \mathrm{C}\right] \\
T_{\infty} & =\text { Temperature of air surrounding the duct element }\left[{ }^{\circ} \mathrm{C}\right] \\
A & =\text { Surface area (Perimeter } * \text { Length) }\left[\mathrm{m}^{2}\right]
\end{array}
$$

The heat transfer by convection to ambient, $Q$, is:

$$
Q=\dot{m} C_{p}\left(T_{\infty}-T_{i}\right)\left[1-\exp \left(-\frac{U A}{m \dot{C}_{p}}\right)\right]
$$

The outlet air temperature can be calculated using the above equation at the given inlet air temperature. Since the inlet temperature at one linkage is the outlet temperature for the connected linkage, the outlet air temperatures at all nodes are solved simultaneously. A square linear system assembled by the Airflow Network model is expressed below:

$$
\{M\}[T]=[B]
$$

where

$$
\begin{array}{ll}
\{\mathrm{M}\} & =\text { Airflow matrix } \\
{[\mathrm{T}]} & =\text { Temperature vector } \\
{[\mathrm{B}]} & =\text { Given boundary conditions }
\end{array}
$$


The zone air temperatures and primary air loop component (fan and coils) outlet conditions are used as prescribed conditions in the Airflow Network model. In addition, the temperature difference across zone loop components (terminal units) is held constant during the calculations. For example, thermal zone temperatures calculated during the previous system time step are used as prescribed temperatures when calculating all other node temperatures. The zone air temperature is assumed constant (prescribed) throughout the Airflow Network iterative solution. The fan and coil outlet air temperatures, and terminal unit temperature differences are assumed constant within an Airflow Network iteration. The sensible heat gains calculated during the Airflow Network solution are then used to predict a new zone air temperature.

\subsubsection{Node Humidity Ratio Calculations}

A brief description of the air node humidity ratio calculation is given below. A detailed description can found in [16]. The following equation is used to calculate humidity ratio distribution across a duct element at the given airflow rate and inlet air humidity ratio:

$$
\dot{m} \frac{d W}{d x}=U_{m} P\left(W_{\infty}-W\right)
$$

where

$$
\begin{array}{ll}
\dot{m} & =\text { Airflow rate }[\mathrm{kg} / \mathrm{s}] \\
P & =\text { Perimeter of a duct element }[\mathrm{m}] \\
W & =\text { Humidity ratio }[\mathrm{kg} / \mathrm{kg}] \\
W_{\infty} & =\text { Humidity ratio of air surrounding the duct element }[\mathrm{kg} / \mathrm{kg}] \\
U_{m} & =\text { Overall moisture transfer coefficient }\left[\mathrm{kg} / \mathrm{m}^{2} \bullet \mathrm{s}\right] \\
& U_{m}=\frac{1}{1}+\frac{1}{h_{m, o}}+\sum \frac{t_{j}}{D_{j}} \\
h_{m, i} & =\text { Inside moisture transfer coefficient }\left[\mathrm{kg} / \mathrm{m}^{2} \bullet \mathrm{s}\right] \\
h_{m, o} & =\text { Outside moisture transfer coefficient }\left[\mathrm{kg} / \mathrm{m}^{2} \bullet \mathrm{s}\right] \\
t_{j} & =\text { Thickness at j-th layer }[\mathrm{m}] \\
\mathrm{D}_{\mathrm{j}} & =\text { Moisture diffusivity at j-th layer }[\mathrm{kg} / \mathrm{m} \bullet \mathrm{s}]
\end{array}
$$

The outlet air humidity ratio at the end of the duct $(\mathrm{x}=\mathrm{L})$ is:

$$
W_{o}=W_{\infty}+\left(W_{i}-W_{\infty}\right) * \exp \left(-\frac{U_{m} A}{\dot{m}}\right)
$$

where

$$
\begin{array}{ll}
W_{i} & =\text { Inlet air humidity ratio }[\mathrm{kg} / \mathrm{kg}] \\
W_{o} & =\text { Outlet air humidity ratio }[\mathrm{kg} / \mathrm{kg}] \\
A & =\text { Surface area (Perimeter * Length) }\left[\mathrm{m}^{2}\right]
\end{array}
$$


The moisture transfer by convection to ambient, $Q_{m}$, is

$$
Q_{m}=\dot{m}\left(W_{\infty}-W_{i}\right)\left[1-\exp \left(-\frac{U_{m} A}{\dot{m}}\right)\right]
$$

The outlet air humidity ratio can be calculated using the above equation at the given inlet air humidity ratio. Since the inlet humidity ratio at one linkage is the outlet humidity ratio for the connected linkage, the outlet air humidity ratio at all nodes are solved simultaneously. A square linear system assembled by the Airflow Network model is expressed below:

$$
\left\{M_{m}\right\}[W]=\left[B_{m}\right]
$$

where

$\left\{\mathrm{M}_{\mathrm{m}}\right\}=$ Airflow matrix

[W] = Humidity ratio vector

$\left[\mathrm{B}_{\mathrm{m}}\right] \quad=$ Given boundary conditions

The zone air humidity ratios and primary air loop component (fan and coils) outlet conditions are used as prescribed conditions in the Airflow Network model. For example, thermal zone humidity ratios calculated during the previous system time step are used as prescribed humidity ratios when calculating all other node humidity ratios. The zone air humidity ratio is assumed constant (prescribed) throughout the Airflow Network iterative solution. The coil outlet air humidity ratio is assumed constant within an Airflow Network iteration. The latent heat gains calculated during the Airflow Network solution are then used to predict a new zone air humidity ratio.

\subsubsection{Sensible and Latent Load Calculations}

The zone sensible and latent loads calculated in the Airflow Network model consist of multizone, duct conduction and leakage. In addition, the impact of infiltration and mixing is accounted for in this calculation. The multizone load only includes incoming airflows from outside (infiltration) and other adjacent zones (mixing) with and without forced-air fan operation. It is divided into two terms: variable and constant. The constant term is the sum of the mass flow rate multiplied by the specific heat for both infiltration and mixing. The variable term includes the impact of zone and outdoor air temperature. Each of these terms is used in the zone energy balance equation. The sensible load items from the multizone load calculations may be written as follows:

$$
\begin{aligned}
& M C P_{\text {airflow }}=m_{\mathrm{inf}} C_{p}+\sum\left(m_{\text {mix }} C_{p}\right) \\
& M C P T_{\text {airflow }}=m_{\mathrm{inf}} C_{p} T_{\text {amb }}+\sum\left(m_{\text {mix }} C_{p} T_{\text {zone }}\right)
\end{aligned}
$$

where

$M C P_{\text {airflow }}=$ Sum of air mass flow rate multiplied by specific heat for infiltration and mixing $[\mathrm{W} / \mathrm{K}]$

$M C P T_{\text {airflow }}=$ Sum of air mass flow rate multiplied by specific heat and temperature for infiltration and mixing [W] 
$\dot{m}_{\text {inf }} \quad=$ Incoming air mass flow rate from outdoors [kg/s]

$\dot{m}_{\text {mix }} \quad$ = Incoming air mass flow rate from adjacent zones $[\mathrm{kg} / \mathrm{s}]$

$T_{a m b}=$ Outdoor air dry-bulb temperature $\left[{ }^{\circ} \mathrm{C}\right]$

$T_{\text {zone }} \quad=$ Adjacent zone air temperature $\left[{ }^{\circ} \mathrm{C}\right]$

The latent load items from multizone load calculations may be written as follows:

$$
\begin{aligned}
& M_{\text {airflow }}=m_{\text {inf }}+\sum m_{\text {mix }} \\
& M W_{\text {airflow }}=m_{\mathrm{inf}} W_{\text {amb }}+\sum m_{\text {mix }} W_{\text {zone }}
\end{aligned}
$$

where

$M_{\text {airflow }}=$ Sum of air mass flow rates for infiltration and mixing $[\mathrm{kg} / \mathrm{s}]$

$M W_{\text {airflow }}=$ Sum of air mass flow rate multiplied by humidity ratio for infiltration and mixing [kg/s ]

$\dot{m}_{\text {inf }} \quad=$ Incoming air mass flow rate from outdoors [kg/s]

$\dot{m}_{\text {mix }} \quad=$ Incoming air mass flow rate from adjacent zones $[\mathrm{kg} / \mathrm{s}]$

$W_{a m b}=$ Outdoor air humidity ratio $[\mathrm{kg} / \mathrm{kg}]$

$W_{\text {zone }}=$ Adjacent zone air humidity ratio $[\mathrm{kg} / \mathrm{kg}]$

The air distribution system (ADS) loads due to duct conduction and leakage depend on the air distribution system component (e.g., duct) location. The air distribution system sensible and latent loads are calculated for each zone as follows:

$$
\begin{aligned}
& Q_{A D S, i}=\sum_{j} Q_{\text {cond }(i, j)}+\sum_{j} Q_{\text {leak }(i, j)} \\
& Q_{A D S, m, i}=\sum_{j} Q_{\text {cond }, m(i, j)}+\sum_{j} Q_{\text {leak }, m(i, j)}
\end{aligned}
$$

where

$Q_{A D S, i}=$ Total sensible load in the i-th zone due to ADS losses [W]

$Q_{\text {cond(ij) }}=$ Duct wall conduction loss at the j-th duct located in the i-th zone [W]

$Q_{\text {leak }(i j)}=$ Sensible supply leak loss at the j-th linkage located in the i-th zone [W]

$Q_{A D S, m, i}=$ Total latent load in the i-th zone due to ADS losses $[\mathrm{kg} / \mathrm{s}]$

$Q_{c o n d, m(i j)}=$ Duct wall vapor diffusion loss at the j-th duct located in the i-th zone $[\mathrm{kg} / \mathrm{s}]$

$Q_{\text {leak,m(ij) }}=$ Latent supply leak loss at the j-th linkage located in the i-th zone $[\mathrm{kg} / \mathrm{s}]$

4.3.2.5 Impacts of Supply Air Constant Volume Fan Control on Load: Cycling vs. Continuous The Airflow Network model currently allows two types of constant volume fans: Fan:ConstantVolume and Fan:OnOff. The Fan:ConstantVolume object has only one type of supply air fan operation mode: 
continuous fan, cycling compressor (ContinuousFanWithCyclingCompressor). However, the Fan:OnOff has two types of supply air fan operation modes: cycling fan, cycling compressor

(CyclingFanAndCompressor) or continuous fan, cycling compressor

(ContinuousFanWithCyclingCompressor). The CyclingFanAndCompressor operation mode is frequently referred to as "AUTO fan", where the compressor(s) and supply air fan operate in unison to meet the zone heating or cooling load, and cycle off together when the heating or cooling load has been met. The ContinuousFanWithCyclingCompressor operation mode is often referred to as "fan ON", where the compressor(s) cycle on and off to meet the zone heating or cooling load but the supply air fan operates continuously regardless of compressor operation. The supply air fan operation mode is specified in an HVAC system object based on a given fan operation mode schedule (e.g., AirLoopHVAC:UnitaryHeatCool object).

The determination of the zone sensible and latent loads caused by multizone airflows and forced air distribution system operation is dependent on the supply air fan operation mode (see Sensible and Latent Load Calculations section above). The zone loads calculated by the Airflow Network model are added to zone sensible and latent balances in the ZonePredictorCorrector module to calculate zone air temperatures and humidity ratios (see Integration of the Airflow Network Model section below). For the case of continuous fan/cycling compressor, the zone loads during forced air distribution system operation are calculated with the system design air mass flow rate without modification, since the system air node conditions (temperature and humidity) reflect the average values for the time step considering the coil/fan on and off periods during the time step.

For the case of cycling fan/cycling compressor, where the forced air distribution system can operate for a portion of the simulation time step, the airflows are determined based on the air distribution system partload ratio (ratio of the average air mass flow rate for the time step divided by the design air mass flow rate). The airflows for the AirflowNetwork:Distribution:Linkage objects are reported during the air distribution system on cycle, since no airflow is assumed during the system off cycle. The airflows for the AirflowNetwork:Multizone:Surface objects are weighted by the air distribution system part-load ratio. The zone loads are the sum of energy losses during both the air distribution system on and off cycle at each system time step. The energy losses when the air distribution system is on are calculated using the system "on" air flow rate multiplied by the air distribution system run time fraction. The energy losses when the air distribution system is off are obtained from the multizone airflow calculations (without forced air through the air distribution system) and these losses are multiplied by (1.0 - system run time fraction), assuming no airflows through the air distribution system when the fan is off. It should be pointed out that duct heat gains or losses during system off-time are not considered. Future effort is need to enhance the model. The formulas used to calculate airflows and zone loads are given below:

Airflow

Airflow $=$ Airflow during ADS on cycle * ADS Part-load ratio + Airflow during ADS off cycle * $(1.0-$ ADS Part-load ratio)

where ADS = Air Distribution System

Zone load

System run time fraction $=$ Maximum run time fraction of coils and fans in the air distribution system

Zone energy losses $=$ Zone energy loss during ADS on cycle * System run time fraction + Zone energy loss during ADS off cycle * (1.0 - System run time fraction)

The calculation of loads due to multizone airflow, without forced air distribution system operation, is performed when the HVAC system is first simulated during a simulation time step (FirstHVACIteration = True). The calculation of loads due to air distribution system operation is performed on subsequent 
iterations within the same simulation time step when the mass flow rate at the supply air fan inlet is greater than 0.0 (and FirstHVACIteration $=$ False $)$.

\subsubsection{Airflow Calculation Procedure using A Supply Variable Air Volume Fan}

The Airflow Network model currently also allows a variable air volume fan type as Fan:VariableVolume. The allowed terminal type is AirTerminal:SingleDuct:VAV:Reheat only. Other types of terminals will be added later.

In general, the supply fan air flow rate in a VAV central system is determined by a sum of terminal flow rates when the Airflow Network model is not applied. When the Airflow Network model is applied and the supply air fan flow rate is given, each terminal flow is determined by pressure resistance of each supply air pathway. It is possible that the delivered air flow rate from the pressure resistance at each terminal may be totally different from the desired flow rate determined by terminal units. Therefore, it is not easy to meet both requirements. The following compromised approach, including possible supply and return leaks in an air distribution system, is implemented.

1. Set up terminal airflows in the Airflow Network module based on the SimVAV subroutine in the HVACSingleDuctSystem module.

2. Require AirflowNetwork:Distribution:Component:LeakageRatio objects to define supply leaks, so that the values of the Effective Leakage Ratio field are used to decide the supply fan flow rates. The base of the ratio will be actual supply fan flow rate, instead of the maximum fan flow rate used in the constant volume fan systems.

3. Assign the supply fan airflow rate based on the sum of all terminal flow rates and all supply leak ratios until it reaches the maximum fan flow rate

$$
\dot{m}_{\text {fan }}=\frac{\sum_{i}^{n} \dot{m}_{i, \text { terminal }}}{1-\sum_{j}^{k} F_{j}}
$$

where

$\dot{m}_{f a n} \quad=$ The supply fan flow rate

$\dot{m}_{i, \text { terminal }} \quad=$ The flow rate at the ith terminal, which is determined in the subroutine SimVAV in the HVACSingleDuctSystem module

$\mathrm{n} \quad=$ Number of terminals

$F_{j} \quad=$ The fraction of the supply fan flow rate at the jth supply leak, given in the

AirflowNetwork:Distribution:Component:LeakageRatio objects.

$\mathrm{k} \quad=$ Number of supply leaks

4. If the calculated supply fan flow rate is above the maximum limit of the supply fan flow rate, and the supply leak ratios remain the same, the supply fan flow rate is set to the maximum limit, and the terminal flow rates are reduced proportionally weighted by a ratio of the maximum supply fan flow rate by input to the calculated supply fan flow rate. Therefore, a sum of all terminal rates and all supply leak rates is equal to the maximum supply fan rate.

$$
R=\frac{\dot{m}_{f a n, m a x}}{\dot{m}_{f a n, c a l}}
$$




$$
\dot{m}_{i, \text { terminal, final }}=\dot{m}_{i, \text { terminal }} * R
$$

where

$\mathrm{R} \quad=$ The ratio of the maximum fan flow rate given in the inputs to the requested fan flow rate based on the above equation

$$
\begin{aligned}
& \dot{m}_{\text {fan,max }} \quad=\text { The maximum supply fan flow rate by input } \\
& \dot{m}_{\text {fan,cal }}=\text { The calculated supply fan flow rate } \\
& \dot{m}_{i, \text { terminal, final }}=\text { The final flow rate at each terminal adjusted by the ratio }
\end{aligned}
$$

\subsection{EXPERIMENTAL COMPARISON}

Petrie [1] conducted experiments in ORNL's Large Scale Climate Simulator (LSCS) to document the effect of attic heat transfer on the thermal performance of a duct in the attic. Steady-state tests were done at severe summer and mild winter conditions. The ceiling R-value was set low at $\mathrm{R}_{\mathrm{Us}}-12\left(\mathrm{R}_{\mathrm{SI}}-2.1\right)$. The duct was tested with and without duct insulation. When insulated the duct was wrapped in $\mathrm{R}_{\mathrm{US}}-5.5\left(\mathrm{R}_{\mathrm{SI}}-1\right)$ and the insulation's outside surface was an aluminum foil cover with thermal emittance of 0.05 . Testing was conducted with no air leakage from the duct. Attic ventilation from eave vents to a ridge vent was varied from none to values achievable by a high level of power ventilation. Tests were conducted with and without a radiant barrier attached to the underside of the roof deck. The duct was run along the floor of the attic, just above the attic insulation. As a caveat, the test space in the LSCS is limited and the duct system occupied $13 \%$ of the plan area of the attic floor. Air temperature inside the ducts as well as attic air, attic insulation and deck temperatures were measured and compared to the AtticSim model. Validation results of the model are shown in Figure 12. Duct air temperature change was predicted within $\pm 0.3^{\circ} \mathrm{F}\left( \pm 0.2^{\circ} \mathrm{C}\right)$ over all tests in which the ducts were installed in the attic. These tests include winter and summer cases with and without radiant barriers over a range of attic ventilation rates ranging from $0 \mathrm{ACH}$ (no flow) to about $50 \mathrm{ACH}$ (power ventilation). Petrie commented that with ducts in the attic, the AtticSim predictions for attic air and insulation temperatures should be accurate within $\pm 10^{\circ} \mathrm{F}\left( \pm 6^{\circ} \mathrm{C}\right)$. 


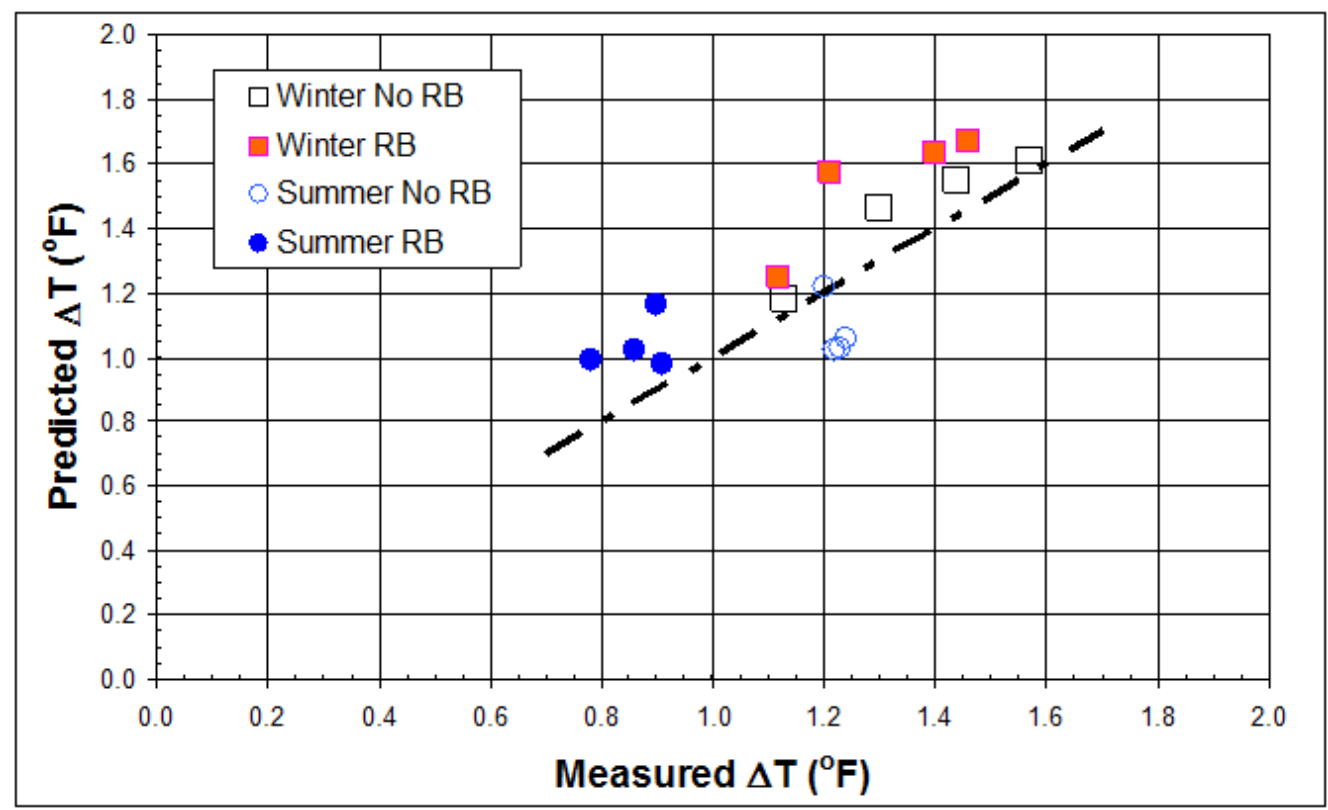

Figure 12. Bulk air temperature change from the inlet to the exit of the test duct predicted by AtticSim (ordinate) and measured in the LSCS (abscissa).

\section{SIMULATION RESULTS}

Simulations were conducted using AtticSim/E+ and EnergyPlus for the hot humid climate of Atlanta, GA (ASHRAE climate Zone 3) and for the colder predominantly heating load climate of Minneapolis, MN (ASHRAE climate zone 6). Two cases were documented for the effects of the duct on attic heat transfer. The first case assumed no air leakage from the duct, also the attic ventilation rate was made the same for AtticSim/E+ and for EnergyPlus simulations. AtticSim has the ability to set a condition flag for input of the hourly ventilation airflow rate. EnergyPlus computed the airflow in the attic and the data was read by AtticSim/E+ for the case with no duct leakage. The second case assumed a $10 \%$ air leakage from the supply duct and a $10 \%$ leakage into the return duct. Walker [17] in his bibliography of duct leakage observed it reasonable to choose a single leakage fraction for both supply and return. Most of the references cited by Walker stated leakage rates of $10 \%$ to $20 \%$ of fan flow. The results of the two cases for ASHRAE Climate zones 3 and 6 are listed in Table 1.

Table 1. The annual heat transfer crossing the attic floor and the annual energy losses for HVAC ducts contained in the attic.

\begin{tabular}{|c|c|c|c|c|c|c|c|c|c|c|}
\hline \multirow{2}{*}{$\begin{array}{c}\text { ASHRAE } \\
\text { Zone } \\
\end{array}$} & \multirow[b]{2}{*}{ City \& State } & \multicolumn{2}{|c|}{ Roof } & \multirow{2}{*}{$\begin{array}{l}\text { Ceiling } \\
\text { R-Value }\end{array}$} & \multirow{2}{*}{$\begin{array}{c}\text { Duct } \\
\text { R-Value }\end{array}$} & \multirow{2}{*}{$\begin{array}{c}\text { Duct } \\
\text { Leakage (\%) }\end{array}$} & \multicolumn{2}{|c|}{ AtticSim/Eplus (kBtu/yr) } & \multicolumn{2}{|c|}{ Eplus (kBtu/yr) } \\
\hline & & SR & TE & & & & Ceiling & Duct & Ceiling & Duct \\
\hline & & & & & & i & & & & \\
\hline Zn_03 & Atlanta, GA & 0.10 & 0.9 & 19 & 8 & 0 & 7552.0 & 11365.0 & 4714.1 & 3297.2 \\
\hline $\mathrm{Zn} \_03$ & Atlanta, GA & 0.10 & 0.9 & 19 & 8 & 10 & 6148.6 & 24247.6 & 3534.1 & 22222.4 \\
\hline & & & & & & ! & & & & \\
\hline Zn_06 & Minneapolis, MN & 0.10 & 0.90 & 49 & 8 & 0 & 7236.1 & 9297.5 & 4900.2 & 3350.4 \\
\hline $\mathrm{Zn}$ & Minneapolis, MN & 0.10 & 0.90 & 49 & 8 & 10 & 4031.9 & 34849.0 & 3706.7 & 29169.2 \\
\hline
\end{tabular}


For the case with no duct leakage and the attic ventilation made equal between the two codes, the results show that EnergyPlus under predicts the annual ceiling heat flow by $60 \%$ of the AtticSim/E+ value and under predicts the annual duct losses by $70 \%$ (yellow highlighted rows Table 1). Computations for the attic air temperature are shown for the summer and winter seasons in Atlanta, GA (Figure 13). Attic air temperatures are very similar for the two codes in part because the two codes used the same boundary condition and set the attic air ventilation exchange the same. Therefore convection heat transfer occurring among the 7 attic surfaces should be about the same. Therefore the differences in annual loads (yellow highlighted rows, Table 1) appears due to the lack of radiation transfer from the interior attic surfaces to the duct as omitted in EnergyPlus. AtticSim/E+ uses the algorithms in AtticSim (Version 12.6) to compute the radiation heat transfer to all surfaces including the ducts. EnergyPlus includes computations for the duct air leakage, duct heat loss (convection and conduction), and radiation energy exchange within the attic, but does not yet include radiant exchange between the attic surfaces and the duct surface. The ducts simulated herein covered about $30 \%$ of the projected area of the attic floor and therefore have a significant effect on the ceiling heat transfer. Similar trends were also observed between the two codes for the case with fixed attic ventilation rate simulated for Minneapolis, MN, Table 1. EnergyPlus underpredicted loads as compared to AtticSim/E+ when both codes assumed the same air exchange rates and have the same incident solar flux on the exterior surfaces.

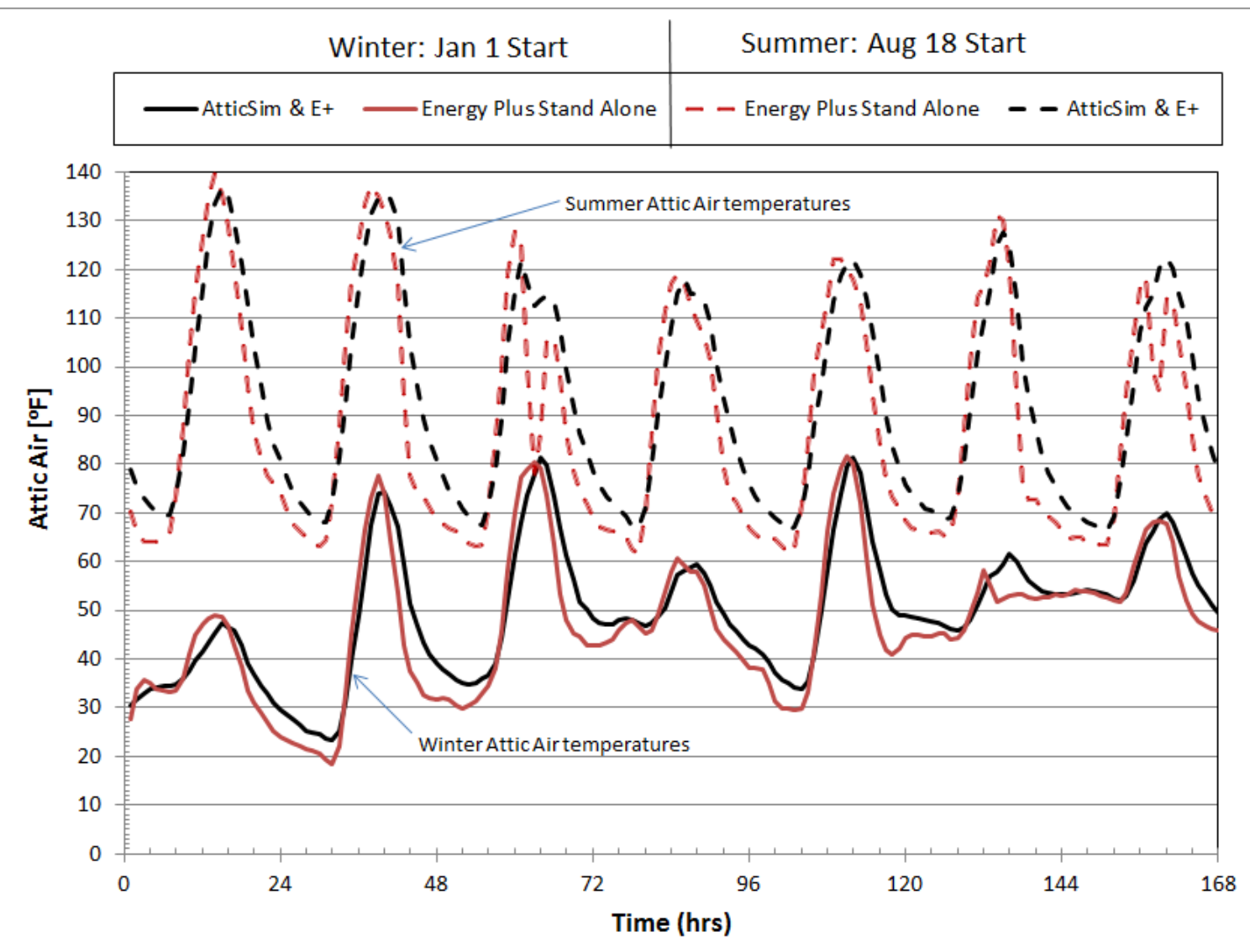

Figure 13. Attic air temperature computed by AtticSim/E+ and by EnergyPlus for the HERS BESTEST home in Atlanta, GA.

Both computer tools were run for the case with the attic containing a 10\% leaky duct. For this case, the attic ventilation rates were computed per the algorithms in each code and therefore attic ventilation was not fixed between the two codes, Figure 14. Ken Childs had conducted CFD modeling to improve the accuracy of AtticSim's attic ventilation model (see Section 4.2.1). Results for EnergyPlus show that it 
over-predicts the attic air temperature and under-predicts the attic ventilation flow rates for both winter and summer operation in Atlanta and Minneapolis. EnergyPlus over-predicts the attic air temperature by as much as $10^{\circ} \mathrm{F}\left(5.6^{\circ} \mathrm{C}\right)$ during winter and summer operation in Atlanta (Figure 14) as compared to AtticSim/E+. It also significantly under-predicts the air exchange rate, which in part, explains the overprediction of attic air temperature.

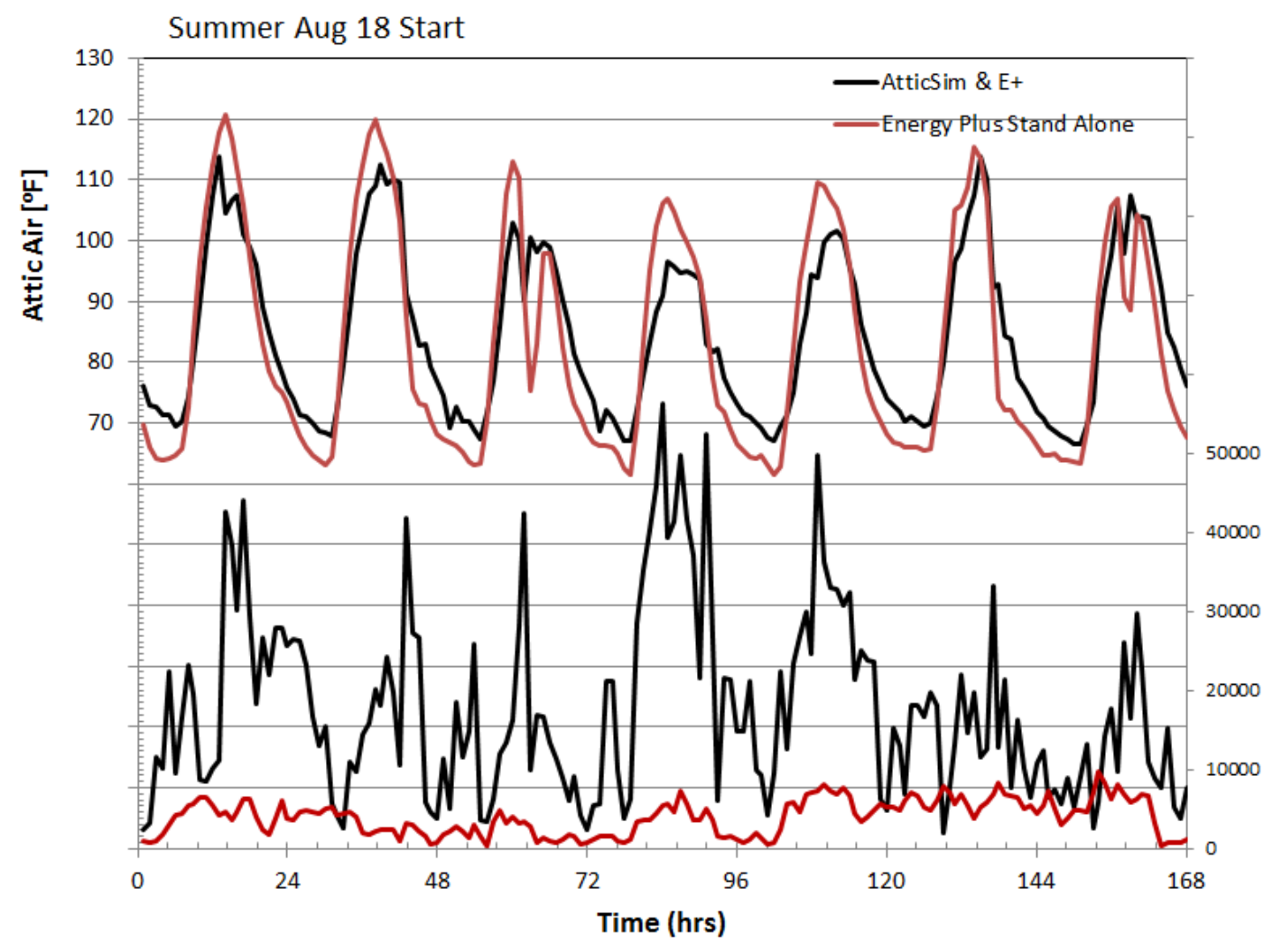

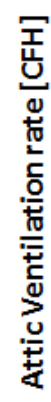

Figure 14. Attic air temperature and air exchange rate for AtticSim/E+ and EnergyPlus computed for Atlanta, GA climate. The attic contains a $10 \%$ leaky duct.

The same trends were also observed for Minneapolis, MN. EnergyPlus over-predicts the attic air temperature by as much as $20^{\circ} \mathrm{F}\left(10^{\circ} \mathrm{C}\right)$ during winter in Minneapolis (Figure 15) as compared to AtticSim/E+. Again, it also significantly under-predicts the air exchange rate, which in part, explains the over-prediction of attic air temperature. 


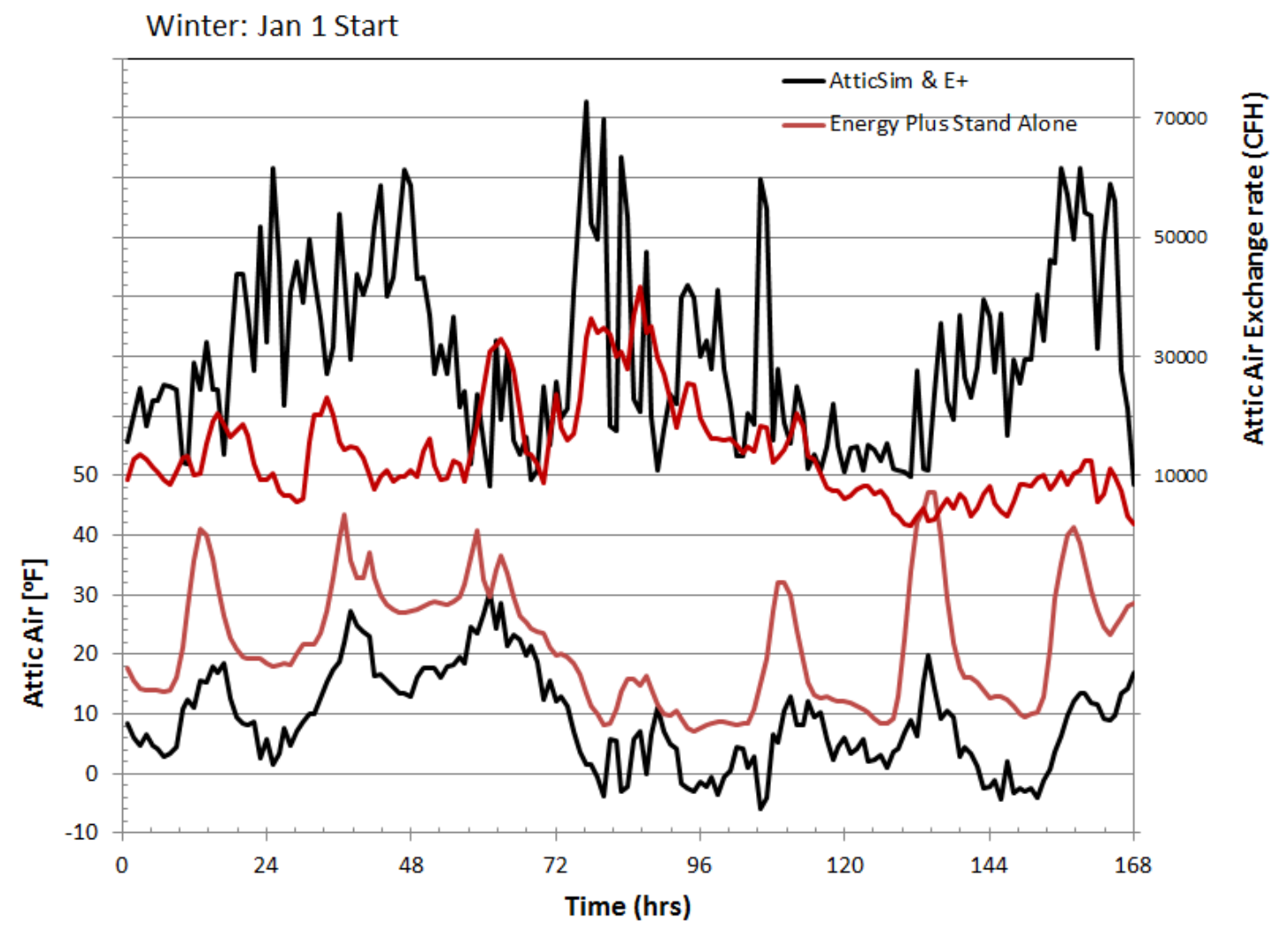

Figure 15. Attic air temperature and air exchange rate for AtticSim/E+ and EnergyPlus computed for Minneapolis, MN climate. The attic contains a $\mathbf{1 0} \%$ leaky duct.

The two observations of higher attic air temperature and lower attic ventilation flow are however not consistent with the trends for ceiling heat transfer and duct load computed by EnergyPlus as compared to AtticSim/E+. For the case with 10\% duct leakage (Table 1), EnergyPlus computes a lower annual ceiling load and a lower annual duct load as compared to AtticSim/E+. But EnergyPlus also computes higher attic air temperature and lower attic ventilation flow as shown in Figure 14 and Figure 15. The heat transfer physics are not consistent and are believed due in part to the omission of radiant exchange to ducts in the attic for the EnergyPlus code and in part to differences in the algorithms used to estimate attic ventilation.

Simulations were conducted for the HERS BESTEST home operating in Atlanta, GA (ASHRAE Climate zone 3) and in Minneapolis, MN (ASHRAE Climate zone 6). EnergyPlus under-predicts the annual ceiling heat flow by $60 \%$ of the AtticSim/E+ value and under-predicts the annual duct losses by $70 \%$. The under-prediction is believed due to EnergyPlus' omission of radiant exchange among the attic surfaces 
and the duct system, attic floor insulation, attic ventilation, solar orientation and weather data were fixed for both simulation engines.

Simulation runs were conducted with a duct having $10 \%$ air leakage from the supply duct and $10 \%$ leakage into the return duct. EnergyPlus predicted the attic air temperature about $10^{\circ} \mathrm{F}\left(5.6^{\circ} \mathrm{C}\right)$ higher for summer operation in Atlanta and about $20^{\circ} \mathrm{F}\left(11.1^{\circ} \mathrm{C}\right)$ higher for winter operation in Minneapolis, MN. EnergyPlus also significantly under-predicts the attic ventilation rate as compared to AtticSim/E+. However, EnergyPlus yielded under-predictions in heat flow crossing the attic floor and the heat gains and losses from ducts in attics as compared to AtticSim/E+. The discrepancies are due in part to the differences computed for ventilation flow rate but are also due in part to the omission of radiant exchange among the attic interior surfaces and the duct housed in the attic.

Results of the study revealed several key issues: (1) during summer operation, the radiation exchange with ducts in the attic is as strong as the losses due to a $10 \%$ duct leakage; (2) during winter operation, duct leakage is the primary loss from the duct system; (3) EnergyPlus' omission of radiant exchange with ducts in attics results in an under-prediction in ceiling heat transfer and an under-prediction in duct energy gains and losses; (4) the EnergyPlus code under-predicts the attic ventilation flow rate for wind driven flows incident on an attic as compared to the results computed by AtticSim, and (5) EnergyPlus computations for ceiling and duct heat gains and losses are not consistent to that observed by AtticSim. EnergyPlus over-predicts attic air temperature and under-predicts attic ventilation but under-predicts ceiling heat transfer and duct heat transfer as compared to AtticSim. Further study is needed to investigate and determine the causes of these inconsistent heat transfer physics.

\section{RECOMMENDATIONS}

We propose two types of recommendations to enhance EnergyPlus. The first type is to enhance EnergyPlus through the addition of AtticSim features. The second type is to enhance EnergyPlus with general capabilities raised by users extracted from the EnergyPlus enhancement list.

\subsection{ATTICSIM FEATURES TO CONSIDER FOR ENERGYPLUS}

Appendix B: Model Comparison Between AtticSim and EnergyPlus provides additional technical background on the mathematical differences between the simulation methods.. The major difference is that AtticSim simulates radiation exchange among duct exterior surfaces and attic interior surfaces, while EnergyPlus only simulates convective heat exchange between ducts and the attic air space. The radiation exchange may be more important than convective exchange in an unconditional attic space. The proposed EnergyPlus enhancement is to add radiation exchange between duct surfaces and attic surfaces.

Here are assumptions to address radiation exchange:

- The view factor between any duct and the floor of the attic enclosure is 0.5 when ducts are exposed to attic air.

- The convective heat transfer is applied when the lower part of ducts is embedded in the attic floor insulation.

- The view factor between any duct and a surface (except the floor) is $0.5 *$ View factor between the surface and the floor.

- $\quad$ Adopt other assumptions listed in X1.3 of ASTM C-1340. 
In addition to radiation exchange enhancement, one more item is proposed to include duct heat gain/loss during system off time. AtticSim calculates duct heat gain/loss even during the system off time. For example, if there is no air flow in the duct for a long time, the temperature of the air in the duct will become closer to the attic air temperature. Impact of duct heat transfer during HVAC system off time could have significant impact if the system cycles frequently. However, EnergyPlus ignores duct heat gain/loss during system off time. An enhancement item listed in Table 2, HVAC_AirLoop_2009_23.doc, addresses this new feature.

A third item is the ability to accurately predict the air exchange rate in attics as affected by wind effects and stack effects. There was significant discrepancy in the prediction of ventilation flow rate between AtticSim and EnergyPlus. A broader review of other attic models is needed and potentially CFD work conducted to support improvement in the ventilation algorithms because the ventilation flow affects attic air temperature which in turn affects ceiling and duct heat transfer.

\subsection{ITEMS TO ENHANCE THE AIRFLOW NETWORK MODEL}

Table 2 lists items extracted from the enhancement list. The first column presents item number. The second column shows file names listed in the enhancement list. The last two columns present item title and a short description for each item.

Table 2. Airflow Network Potential Features

\begin{tabular}{|c|c|c|c|}
\hline Item & File Names & Title & Description \\
\hline 1 & $\begin{array}{l}\text { Zone_2007_ } \\
\text { 06.doc }\end{array}$ & $\begin{array}{l}\text { Add Model for Zone Induced } \\
\text { Air by a Constant Volume } \\
\text { Fan }\end{array}$ & $\begin{array}{l}\text { Add a model for zone-induced air flow by a } \\
\text { constant volume fan. This will allow EnergyPlus to } \\
\text { model Case MA204 of the IEA Multi-zone air flow } \\
\text { test suite. }\end{array}$ \\
\hline 2 & $\begin{array}{l}\text { HVAC_2007 } \\
\text { _64.doc }\end{array}$ & $\begin{array}{l}\text { Airflow Network Model: Air } \\
\text { Distribution System Thermal } \\
\text { Capacitance }\end{array}$ & $\begin{array}{l}\text { Energy losses from an air distribution system in } \\
\text { the Airflow Network model are calculated based } \\
\text { on a steady-state condition when the supply fan } \\
\text { turns on, and are assumed to be zero when the } \\
\text { fan is off. This assumption neglects losses from } \\
\text { the air distribution system during the system off } \\
\text { periods. }\end{array}$ \\
\hline 3 & $\begin{array}{l}\text { Windows_2 } \\
008 \_03 . d o c\end{array}$ & $\begin{array}{l}\text { Naturally Ventilated Double } \\
\text { Facades Using Airflow } \\
\text { Network Model }\end{array}$ & $\begin{array}{l}\text { Add naturally ventilated air flow using the Airflow } \\
\text { Network model and enhance hybrid ventilation } \\
\text { controls to switch between natural and forced } \\
\text { ventilation through the window cavity. }\end{array}$ \\
\hline 4 & $\begin{array}{l}\text { HVAC_AirLo } \\
\text { op_2009_05 } \\
\text {.doc }\end{array}$ & $\begin{array}{l}\text { Improve Radiant and } \\
\text { Convective Heat Transfer } \\
\text { Physics Relevant to Ducts } \\
\text { Located in Ventilated Attics }\end{array}$ & $\begin{array}{l}\text { Add radiation exchange between duct surfaces } \\
\text { and zone surfaces and improve convective heat } \\
\text { exchange correlations. }\end{array}$ \\
\hline 5 & $\begin{array}{l}\text { HVAC_AirLo } \\
\text { op_2009_06 } \\
\text {.doc }\end{array}$ & $\begin{array}{l}\text { Allow Multiple Air Primary } \\
\text { Loops in the Airflow Network } \\
\text { Model }\end{array}$ & $\begin{array}{l}\text { Allow the Airflow Network model to simulate } \\
\text { energy losses for air distribution systems and } \\
\text { associated interactions among HVAC systems, } \\
\text { envelope, and outdoors caused by unbalanced } \\
\text { return and supply leaks in the multiple air } \\
\text { distribution systems in a large commercial } \\
\text { building. }\end{array}$ \\
\hline
\end{tabular}




\begin{tabular}{|c|c|c|c|}
\hline 6 & $\begin{array}{l}\text { HVAC_AirLo } \\
\text { op_2009_07 } \\
\text {.doc }\end{array}$ & $\begin{array}{l}\text { Enhance the Airflow Network } \\
\text { Model to Provide Specified } \\
\text { Outdoor Air Flow Rates }\end{array}$ & $\begin{array}{l}\text { Improve the model to simulate the same outdoor } \\
\text { airflow rates specified in the Controller:OutdoorAir } \\
\text { object }\end{array}$ \\
\hline 7 & $\begin{array}{l}\text { HVAC_AirLo } \\
\text { op_2009_23 } \\
\text {.doc }\end{array}$ & $\begin{array}{l}\text { Enhance Airflow Network } \\
\text { Model to Include Duct } \\
\text { System Energy Losses } \\
\text { During System-off Periods }\end{array}$ & $\begin{array}{l}\text { Duct conduction losses during HVAC system off- } \\
\text { cycles can be significant. This work will add a } \\
\text { simple model to calculate off-cycle duct system } \\
\text { losses. }\end{array}$ \\
\hline 8 & $\begin{array}{l}\text { Ventilation } \\
\text { 2010_01.do } \\
\text { c }\end{array}$ & $\begin{array}{l}\text { Add more vent control } \\
\text { options in the Airflow } \\
\text { Network model }\end{array}$ & $\begin{array}{l}\text { Extend Airflow Network for more control options } \\
\text { needed for natural ventilation }\end{array}$ \\
\hline 9 & $\begin{array}{l}\text { Ventilation } \\
\text { 2010_02.do } \\
\text { c }\end{array}$ & $\begin{array}{l}\text { Allow a horizontal opening } \\
\text { exposed to outdoors in the } \\
\text { Airflow Network model }\end{array}$ & $\begin{array}{l}\text { Allow Airflow } \\
\text { Network:MultiZone:Component:HorizontalOpenin } \\
\text { g exposed to outdoors }\end{array}$ \\
\hline 10 & $\begin{array}{l}\text { Ventilation } \\
\text { 2010_03.do } \\
\text { C }\end{array}$ & $\begin{array}{l}\text { Add a new solver with } \\
\text { relaxation in the Airflow } \\
\text { Network model }\end{array}$ & add option for different solver for Airflow Network \\
\hline 11 & $\begin{array}{l}\text { Ventilation_- } \\
\text { 2014_01.pdf }\end{array}$ & $\begin{array}{l}\text { Advanced window } \\
\text { operational modeling }\end{array}$ & $\begin{array}{l}\text { Enhance the Airflow Network model to provide } \\
\text { more practical and advanced operation controls }\end{array}$ \\
\hline
\end{tabular}

\section{REFERENCES}

[1] Petrie, T.W., Wilkes, E.W., Childs, P. W. and Christian, J.E. 1998. "Effect of Radiant Barriers and Attic Ventilation on Residential Attics and Attic Duct Systems: New tools for Measuring and Modeling” ASHRAE Summer Transactions, Vol. 104, Part 2, pp. 1175-1192.

[2] Kusuda, T. 1969. “Thermal Response Factors for Multi-Layer Structures of Various Heat Conduction Systems,” ASHRAE Transactions, Vol. 75, Part 1, pp. 246-271.

[3] Wilkes, K.E. 1991.Thermal Model of Attic Systems with Radiant Barriers. ORNL/CON-262. Oak Ridge, Tenn.: Oak Ridge National Laboratory.

[4] Miller, W. A., Kriner, S. and Desjarlais, A., "The Tradeoff between Solar Reflectance and Above Sheathing Ventilation for Metal Roofs on Residential and Commercial Buildings" Thermal Performance of the Exterior Envelopes of Buildings, XII, proceedings of ASHRAE THERM XII, Clearwater, FL., Dec. 2013.

[5] Judkoff, Ron and Neymark, Joel. NREL/TP-472-7332a. 1995a. Home Energy Rating System Building Energy Simulation Test (HERS BESTEST), Volume 1, used with “EnergyPlus: DOE's Next Generation Simulation Program.”

[6] NREL. 1995b. TMY2s. Typical meteorological years derived from the 1961-1990 national solar radiation database. Data Compact Disk. Golden, CO: National Renewable Energy laboratory.

[7] DOE, 2013. EnergyPlus Input/Output Reference and Engineering Reference for EnergyPlus version 8.1. Available: http://apps1.eere.energy.gov/buildings/energyplus/energyplus_documentation.cfm

[8] Gu, L, 2007, “Airflow Network Modeling in EnergyPlus,” In Proceedings of the Building Simulation 2007 Conference, Beijing, China.

[9] Miller, W.A., Graves, R. and Atherton, S. 2011. “A Prototype Roof Deck Designed to Self-Regulate Deck Temperature and Reduce Heat Transfer,” NRCA International Roofing Symposium, Washington D.C, Sep 2011. 
[10] Cummings, J.B., Toole J.J., and Moyer, N.A. 1990. Duct Leakage Impacts on Airtightness, Infiltration, and Peak Electrical Demand in Florida Homes. Professional Paper, Florida Solar Energy Center, Cocoa, FL, FSEC-PF-212-90.

[11] Parker, D., Fairey, P., and Gu, L. 1993. Simulation of the effects of duct leakage and heat transfer on residential space cooling energy use. Energy and Buildings, 20(2): 97-113.

[12] ASTM C1340. 2009. Standard Practice for Estimation of Heat Gain or Loss Through Ceilings Under Attics Containing Radiant Barriers by Use of a Computer Program, Annual Book of ASTM Standards, Vol. 04.06, Conshohocken, PA

[13] Walton, G. N. 1989. “AIRNET - A Computer Program for Building Airflow Network Modeling,” NISTIR 89-4072, National Institute of Standards and Technology, Gaithersburg, Maryland.

[14] Dols, W. S. \& G. N. Walton. 2002. “CONTAMW 2.0 User Manual,” NISTIR 6921, National Institute of Standards and Technology, Gaithersburg, Maryland.

[15] Walton, G. N. \& W. S. Dols. 2003. "CONTAM 2.1 Supplemental User Guide and Program Documentation,” NISTIR 7049, National Institute of Standards and Technology, Gaithersburg, Maryland.

[16] Swami, M. V., L. Gu, \& V. Vasanth. 1992. "Integration of Radon and Energy Models for Building,” FSEC-CR-553-92, Florida Solar Energy Center, Cocoa, Florida.

[17] Walker, I.S. 1998. Technical background for default values used for forced air systems in proposed ASHRAE standard 152P. ASHRAE Trans., 104(1); presented at ASHRAE TC 6.3 Symposium, January 1998. LBNL 40588.

[18] Henninger, R. H. and M. Witte, 2013, EnergyPlus Testing with HVAC Equipment Performance Tests CE300 to CE545 from ANSI/ASHRAE Standard 140-2011, EnergyPlus Version 8.1.0.009 


\section{AtticSim12-6 Input}

$9 / 19 / 2013$

\section{Line 1}

1) Descriptive title of case. Maximum length of 100 characters.

\section{Line 2}

1) Weather file to be used.

2) Format of weather file: 1 for EnergyPlus, 2 for user-created.

\section{Line 3}
1) Month to start calculation [iStrtMon]
2) Day of month to start calculation [iStrtDay]
3) Month to end calculation [iEndMon]
4) Day of month to end calculation [iEndDay]

\section{Line 4}

This line contains seven entries that deal with the geometry of the attic.

1) length of the attic in feet [AL]

2) width of the attic in feet [W]

3) pitch of side 1 of roof in degrees [PITCH1]

4) pitch of side 2 of roof in degrees [PITCH2]

Enter 90.0 for a shed roof.

5) orientation of the house [ORIENT]

This is the direction (in degrees clockwise from north) that roof side 1 (attic component 2) faces. ( $0 \leq$ ORIENT <360) For example, for an east facing roof enter 90 .

6) height of the eave walls in feet [H1]

The attic model includes vertical walls at the eaves. If there are no vertical walls in the attic to be simulated a small value should be entered (e.g., 0.001). This will not affect the simulation to any appreciable extent.

7) roughness index for roof surface [ISURF]

1 Smooth (e.g., standing-seam metal roof)

2 Slightly rough

3 Rough (e.g., asphalt shingle roof) 
4 Very rough

5 Blunt (e.g., tile roof)

\section{Line 5}

This line contains three entries that specify the attic vent areas.

1) area of one soffit vent, $\mathrm{ft}^{2}$ (area of opposite soffit, if present, is assumed equal) [Asoffit]

2) area of ridge vent, $\mathrm{ft}^{2}$ [Aridge]

3) area of one gable vent, $\mathrm{ft}^{2}$ (area of opposite soffit is assumed equal) [Agable]

\section{Line 6}

1) Heating setpoint temperature, ${ }^{\circ} \mathrm{F}$ [TheatSP]

2) Cooling setpoint temperature, ${ }^{\circ} \mathrm{F}$ [TcoolSP]

3) Heating design point outdoor temperature, ${ }^{\circ} \mathrm{F}$ [TheatDP]

4) Cooling design point outdoor temperature, ${ }^{\circ} \mathrm{F}[\mathrm{TcoolDP}]$

5) Indoor/outdoor temperature difference due to internal loads, ${ }^{\circ} \mathrm{F}$ [deltaT]

6) Fixed relative humidity inside the house, percent [HUMI]

7) Fraction of the hour that the equipment is running, dimensionless [ONTIMEAVG] This value may be overridden if an auxiliary file is used. If a value of zero is entered then a fraction ontime will be calculated for each hour using the outdoor air temperature along with the first five values on this line.

8) Exfiltration air flow from the house into the attic space in lb/h EXFIL]

\section{Line 7}

1) Constant term (a) in equation for cooling EER as function of temperature, Btu/Wh [EERa] $\mathrm{EER}=\mathrm{a}+\mathrm{bT}$ where $\mathrm{T}$ is outdoor temperature in ${ }^{\circ} \mathrm{F}$

2) Slope (b) in equation for cooling EER as function of temperature, Btu/Wh- ${ }^{\circ} \mathrm{F}$ [EERb]

The remainder of the input data is entered in data blocks identified by a keyword on the line immediately preceding the data. Some of the data blocks are required while others only appear if certain features are to be included in the model.

\section{USER-SUPPLIED BOUNDARY CONDITION DATA BLOCK}

This data block is included only when the user wishes to supply certain parameters in an auxiliary file rather than have the code calculate them. 


\section{Line U0}

1) Keyword “USER' in all caps beginning in column 1

\section{Line U1}

1) File name of auxiliary file containing "known” values for parameters that may be used rather than calculating these parameters.

\section{Line U2}

This line contains 19 integer flags that indicate which values from the auxiliary file are to be used. A " 0 " indicates that the parameter is to be calculated in the simulation, and a " 1 " indicates that the parameter is known and the simulation should use this known value. The index identifies a particular parameter as follows:

1) temperature - top surface of attic floor (attic component 1)

2) temperature - bottom surface of side 1 of the roof (attic component 2)

3) temperature - bottom surface of side 2 of the roof (attic component 3 )

4) temperature - inside surface of gable 1 (attic component 4)

5) temperature - inside surface of gable 2 (attic component 5)

6) temperature - inside surface of eave wall 1 (attic component 6)

7) temperature - inside surface of eave wall 2 (attic component 7)

8) temperature - bottom surface of attic floor (attic component 1)

9) temperature - top surface side 1 of roof (attic component 3)

10) temperature - top surface side 2 of the roof (attic component 4)

11) temperature - outside surface of gable 1 (attic component 4)

12) temperature - outside surface of gable 2 (attic component 5)

13) temperature - outside surface of eave wall 1 (attic component 6)

14) temperature - outside surface of eave wall 2 (attic component 7)

15) attic ventilation rate

16) attic ventilation air temperature

17) indoor air temperature

18) HVAC fraction on-time

19) inlet temperature, mass flow rate and leakage rate for all duct runs

\section{DUCT DATA BLOCK}

This data block is optional.

\section{Line D0}

1) Keyword "DUCT" in all caps beginning in column 1 


\section{Line D1}

This line specifies the number of duct runs in the attic.

1) Number of supply duct runs [NSUPLY]

2) Number of return duct runs [NRETRN]

\section{Line D2}

This line specifies the temperature of the air leaving the HVAC equipment.

1) temperature for heating mode, ${ }^{\circ} \mathrm{F}[\operatorname{XTDUCTIN}(1)]$

2) temperature for cooling mode, ${ }^{\circ} \mathrm{F}$ [XTDUCTIN(2)]

\section{Line D3}

This line is repeated once for each duct run. Inputs for the supply ducts are listed first, followed by input for the return ducts. Up to 25 duct runs are allowed - in any combination of supply and return ducts. It is suggested that the ducts should be numbered sequentially, starting with the run nearest the air-handling equipment. Node numbers identify how the ducts are connected to each other. The exit for one duct run can be the inlet for one or more duct runs next downstream, and the junction will occur at a particular node. Two layers of insulation are allowed in order to handle different insulation strategies. For example, the ducts may be sheet metal with insulation on the outside, on the inside or on both sides. Even if only one layer of insulation is to be modeled, nonzero values for both conductivities must be entered as in order to avoid a divide-check. All ducts do not have to have the same shape. However, the model does not calculate any flow disturbance due to a change in size or shape of the ducts.

1) Unique duct identification number. [ND(I)]

2) Node number at duct entrance. [NINLET(I)]

3) Node number at duct exit [NEXIT(I)]

4) Duct shape: $0=$ round, $1=$ rectangular. [ISHAPE(I)]

5) Duct inner layer thermal conductivity, Btu/h-ft- ${ }^{\circ} \mathrm{F}[\mathrm{AKI}(\mathrm{I})]$

6) Duct outer layer thermal conductivity, Btu/h-ft- ${ }^{\circ} \mathrm{F}[\mathrm{AKO}(\mathrm{I})]$

7) heat capacity per unit length (including duct wall and insulation), Btu/ft- ${ }^{\circ} \mathrm{F}$ [RHOC(I)]

8) duct run length, $\mathrm{ft}$ [ALS(I)]

9) mass flow rate entering duct run in heating mode, lb/h [XMDOTIN(I,1)]

10) mass leakage to or from the duct per unit length in heating mode, lb/h-ft [XMDOTLK(I,1)]

11) mass flow rate entering duct run in cooling mode, lb/h [XMDOTIN(I,2)]

12) mass leakage to or from the duct per unit length in cooling mode, lb/h-ft [XMDOTLK(I,2)]

13) emittance of the external surface of the duct, dimensionless [EODUCT(I)]

\section{Line D4}


If the duct run is round, this line will contain three entries:

1) inside diameter of the inner layer of the duct insulation system, $\mathrm{ft}$ [DI]

2) outside diameter of the inner layer of the duct insulation system, ft [DW] This is also the inside diameter of the outer layer of duct insulation.

3) outside diameter of the outer layer of duct insulation, ft [DO]

If the duct run is rectangular, this line will contain six entries:

1) inside width of the inner layer of duct insulation, $\mathrm{ft}$ [XI]

2) inside height of the inner layer of duct insulation, $\mathrm{ft}$ [YI]

3) outside width of the inner layer of duct insulation, $\mathrm{ft}$ [XW]

4) outside height of the inner layer of duct insulation, ft [YW]

5) outside width of the outer layer of duct insulation, ft [XO]

6) outside height of the outer layer of duct insulation, $\mathrm{ft}$ [YO]

\section{STRUCTURE DATA BLOCK}

This data block or the CTF data block is required - but not both. It defines the conduction paths for all of the components enclosing the attic space.

\section{Line S0}

1) Keyword “STRUCTURE” in all caps beginning in column 1

The following lines define conduction paths for all of the components enclosing the attic space. Each component can have either one or two conduction paths associated with it. Two conduction paths allows for inclusion of thermal bridges. The components are entered in the following order:

1. Attic floor/house ceiling (attic component 1 )

2. Roof 1 (attic component 2)

3. Roof 2 (attic component 3)

4. Gable 1 (attic component 4)

5. Gable 2 (attic component 5)

6. Eave wall 1 (attic component 6)

7. Eave wall 2 (attic component 7)

8. Roof 1 ASV (attic component 8) - omitted if ASV not modeled

9. Roof 2 ASV (attic component 9) - omitted if ASV not modeled or ASV modeled on a shed roof

There will be one S1 line and one or more S2 lines for each conduction path, and one or two conduction paths for each component. The layers are defined beginning with the layer farthest from the attic space and ending with the layer closest to the attic space except for the attic floor (house ceiling) which are entered in the reverse order. 


\section{Line S1}

1) number of layers for this conduction path[NL]

2) area fraction for this conduction path. Enter 1.0 if this is the only conduction path for this component. [AreaFrac]

3) Description of conduction path. Maximum of 60 characters enclosed in quotes. [TITLE]

\section{Lines S2-S(NL+1)}

1) material name. Maximum of 16 characters enclosed in quotes. [MNAMES(I)]

2) thickness of layer, ft [THICK(I)]

3) thermal conductivity, Btu/h-ft- ${ }^{\circ} \mathrm{F}[\mathrm{COND}(\mathrm{I})]$

4) specific heat, Btu/lb- ${ }^{\circ} \mathrm{F}[\mathrm{SPHT}(\mathrm{I})]$

5) density, $\mathrm{lb} / \mathrm{ft}^{3}[\mathrm{DENS}(\mathrm{I})]$

\section{CTF DATA BLOCK}

This data block or the STRUCTURE data block is required - but not both. This data block supplies conduction transfer functions that have been previously calculated.

\section{Line C0}

1) Keyword “CTF” in all caps beginning in column 1

The following lines define conduction transfer functions (CTF) for all of the components enclosing the attic space. The components are entered in the following order:

1. Attic floor/house ceiling (attic component 1 )

2. Roof 1 (attic component 2)

3. Roof 2 (attic component 3)

4. Gable 1 (attic component 4)

5. Gable 2 (attic component 5)

6. Eave wall 1 (attic component 6)

7. Eave wall 2 (attic component 7)

8. Roof 1 ASV (attic component 8) - omitted if ASV not modeled

9. Roof 2 ASV (attic component 9) - omitted if ASV not modeled or ASV modeled on a shed roof

There will be one C1 line and multiple C2 lines for each component. Components 8 and 9 should only be included when ASV is being modeled.

\section{Line C1}


1) number of conduction transfer functions supplied [N(I)]

2) surface-to-surface $U$ value $[U(I)]$

3) common ratio for conduction transfer functions [CR(I)]

4) temperature-dependence factor for thermal conductivity [BETA]

\section{Line C2}

1) $X$ conduction transfer function $[X(I, J)]$

2) $Y$ conduction transfer function $[Y(I, J)]$

3) $\mathrm{Z}$ conduction transfer function $[\mathrm{Z}(\mathrm{I}, \mathrm{J})]$

\section{END OF INPUT}

This block is required. It marks the end of the input data. Any following lines will not be read.

\section{Line E0}

1) Keyword "END" in all caps beginning in column 1

\section{AUXILIARY FILE}

This format for this file is comma separated variables (CSV). The first line in the file must correspond with the first hour of the simulation to be performed. There is one line in the file for every hour of simulation that is to be performed. Each line of the auxiliary file contains the values shown in the table below. A zero can be entered for values that are not referenced in the "USER SUPPLIED BCs DATA BLOCK".

Table 3. Auxiliary File used to place boundary conditions from EnergyPlus on AtticSim simulations.

\begin{tabular}{|l|l|}
\hline Variable Name & Definition \\
\hline$($ TIS $(I, 1), I=1,7)$ & Inside surface temperature for component I \\
\hline$($ TOS $(I, 1), I=1,7)$ & Outside surface temperature for component I \\
\hline VDOT & Volumetric flow rate of air through attic \\
\hline TVENT & Temperature of vent air entering attic \\
\hline TI & Indoor air temperature \\
\hline ONTIME & Fraction of hour HVAC equipment is on \\
\hline
\end{tabular}




\begin{tabular}{|l|l|}
\hline DUCTTIN & Temperature of air exiting HVAC equipment \\
\hline $\begin{array}{l}\text { (DUCTMIN (I) , DUCTLKG (I ), I=1, NT } \\
\text { OT })\end{array}$ & Flow rate and leakage rate for each duct run \\
\hline
\end{tabular}

\section{USER-SUPPLIED WEATHER FILE}

This format for this file is comma separated variables (CSV

\section{Line 1}

1) Location - up to 12 character location identifier (e.g., name of city)

2) Latitude (degrees)

3) Longitude (degrees) (example: $80^{\circ} \mathrm{W}$ entered as -80 )

4) Time zone (5=Eastern, $6=$ Central, etc.)

5) Elevation (ft)

6) Ground reflectance (fraction)

7) Solar data available: $1=$ total horizontal and direct, $2=$ horizontal only, $3=$ =none

\section{Line 2+}
1) Month
2) Day of month
3) Hour of day
4) Dry bulb temperature $\left({ }^{\circ} \mathrm{F}\right)$
5) Dew point temperature $\left({ }^{\circ} \mathrm{F}\right)$
6) Atmospheric pressure (psi)
7) Infrared radiation from sky on horizontal surface $\left(B t u / h-\mathrm{ft}^{2}\right)$
8) Total solar radiation on a horizontal surface $\left(\mathrm{Btu} / \mathrm{h}-\mathrm{ft}^{2}\right)$
9) Direct normal solar radiation $\left(\mathrm{Btu} / \mathrm{h}-\mathrm{ft}^{2}\right)$
10) Diffuse horizontal solar radiation $\left(\mathrm{Btu} / \mathrm{h}-\mathrm{ft}^{2}\right)$
11) Wind direction (degrees)
12) Wind speed (mph)
13) Cloud amount - fraction of sky covered with clouds
14) Cloud type
15) Atmospheric clearness 


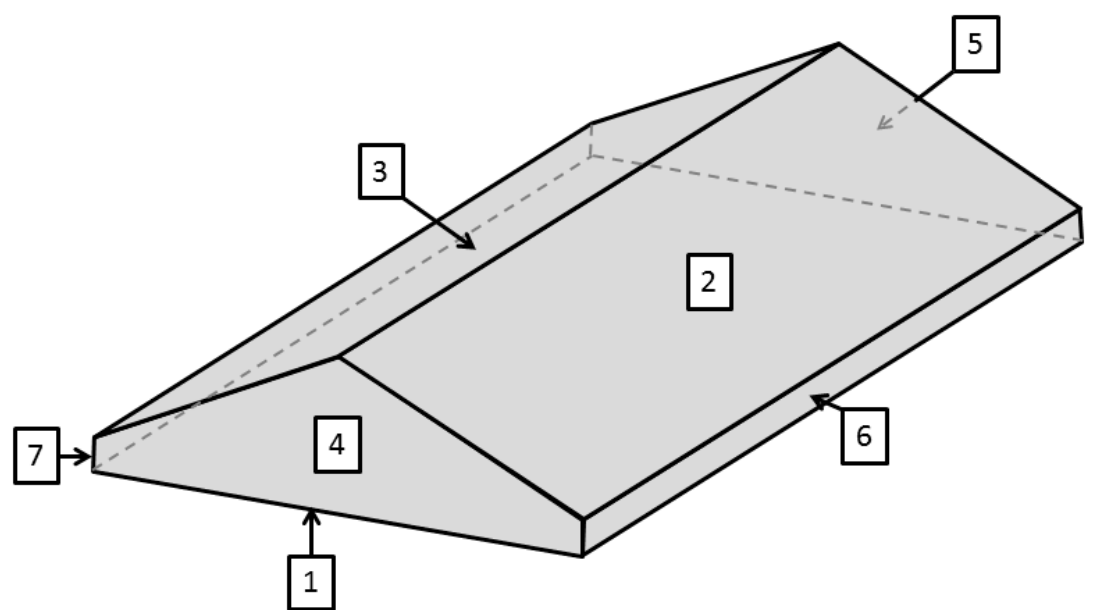

1. Attic floor

3. Roof side 2

5. Gable 2

7. Eave wall 2

2. Roof side 1

4. Gable 1

6. Eave wall 1

Figure 16. Attic components for conventional roof without ASV

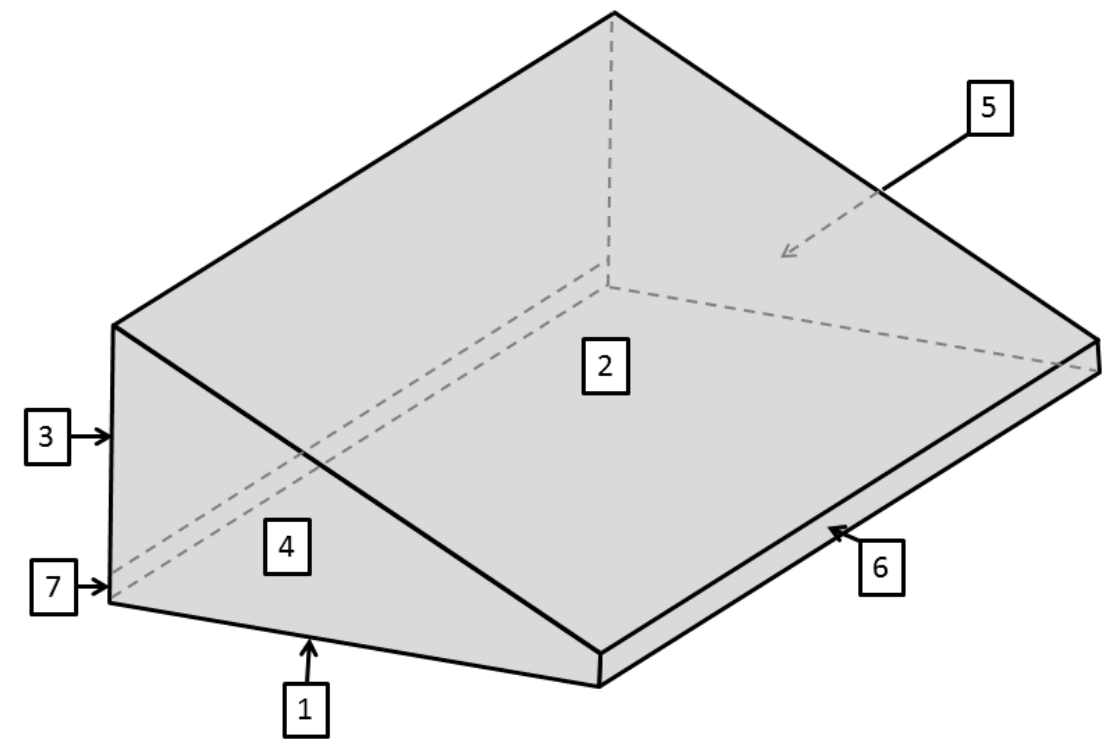

1. Attic floor

3. Roof side 2

5. Gable 2

7. Eave wall 2

2. Roof side 1

4. Gable 1

6. Eave wall 1

Figure 17. Attic components for shed roof without ASV 


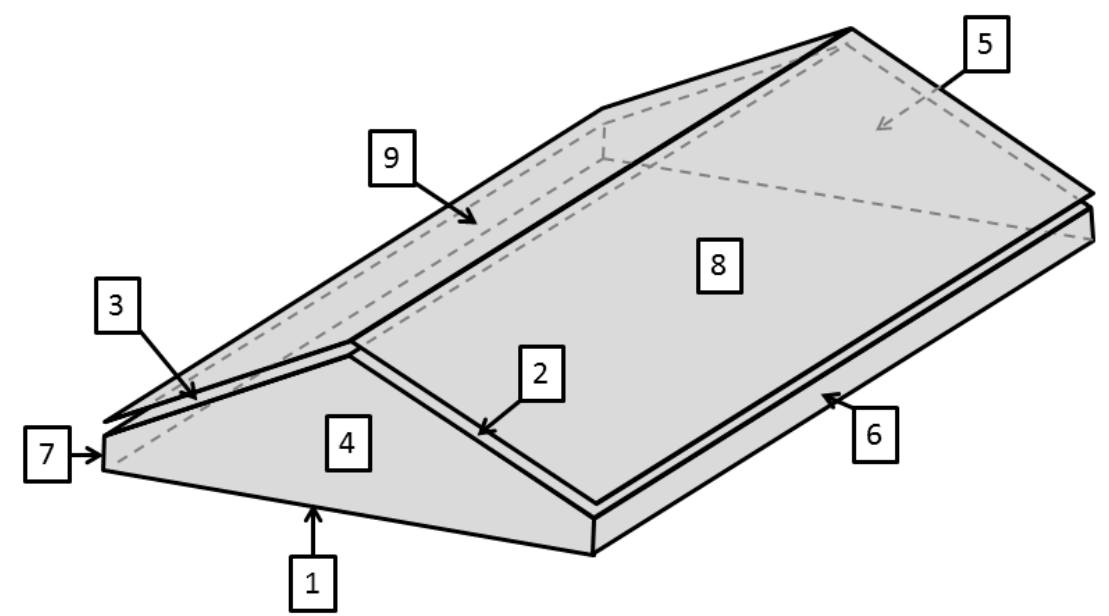

1. Attic floor

3. Roof side 2

5. Gable 2

7. Eave wall 1

9. ASV side 2

2. Roof side 1

4. Gable 1

6. Eave wall 1

8. ASV side 1

Figure 18. Attic components for conventional roof with ASV

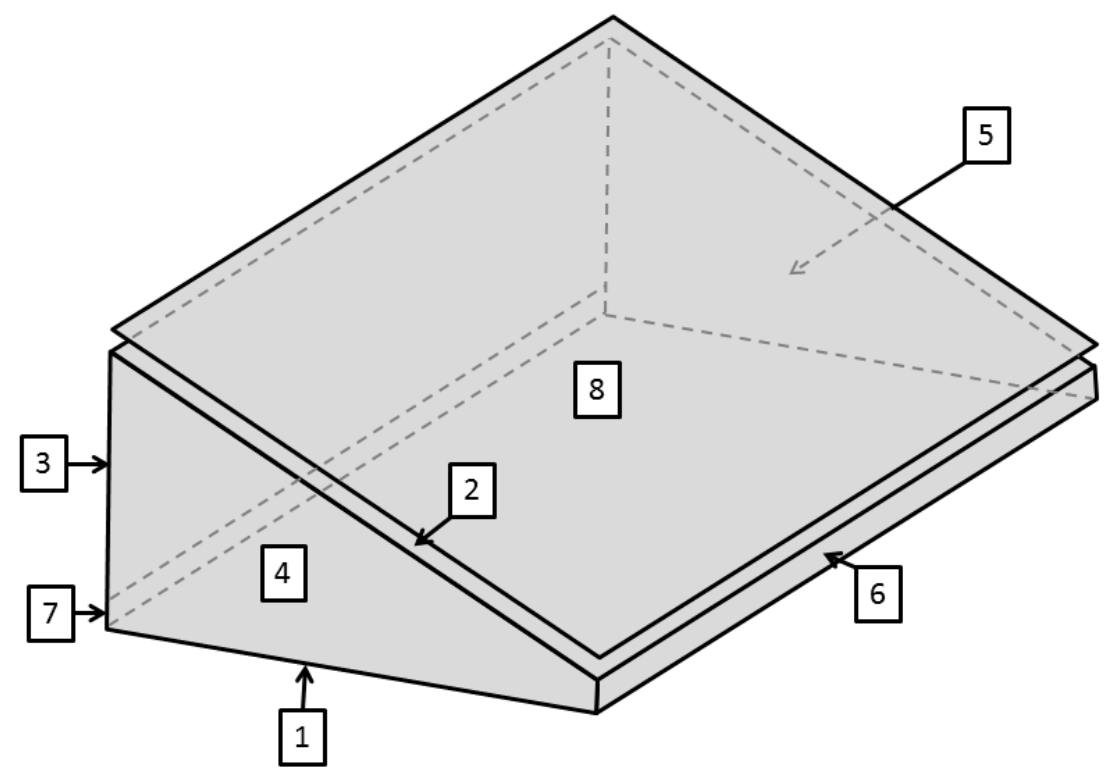

1. Attic floor

3. Roof side 2

5. Gable 2

7. Eave wall 2

2. Roof side 1

4. Gable 1

6. Eave wall 1

8. ASV

Figure 19. Attic components for shed roof with ASV 


\section{APPENDIX B: MODEL COMPARISON BETWEEN ATTICSIM AND ENERGYPLUS}

Section 6 Method of Calculation is used as a base for comprehensive comparison with EnergyPlus attic model. The following table provides calculation method comparisons between AtticSim and EnergyPlus in detail.

Table 4. Detailed model comparison between AtticSim and EnergyPlus

\begin{tabular}{|c|c|c|c|}
\hline $\begin{array}{l}\text { 6. Method } \\
\text { of } \\
\text { Calculation }\end{array}$ & AtticSim & EnergyPlus & $\begin{array}{l}\text { Note } \\
\text { From E+ point of } \\
\text { view }\end{array}$ \\
\hline $\begin{array}{l}6.3 \\
\text { Conduction }\end{array}$ & $\begin{array}{l}\text { Thermal response factor and conduction transfer } \\
\text { functions }\end{array}$ & $\begin{array}{l}\text { Conduction transfer function (CTF) and finite difference } \\
\text { method }\end{array}$ & $\begin{array}{l}\text { Both response } \\
\text { factors and CTFs } \\
\text { are similar, but } \\
\text { must be converted. }\end{array}$ \\
\hline \multirow[t]{2}{*}{ CTF } & $\begin{aligned} Q I & =\sum_{j=0}^{N} Z(j)(T I S(j)-T R) \\
& -\sum_{j=0}^{N} Y(j)(T O S(j)-T R)+C R Q I^{\prime} \\
Q O & =\sum_{j=0}^{N} Y(j)(T I S(j)-T R) \\
& -\sum_{j=0}^{N} X(j)(T O S(j)-T R)+C R Q O^{\prime}\end{aligned}$ & $\begin{array}{l}\text { For the inside heat flux } \\
q_{k i}^{\prime \prime}(t)=-Z_{o} T_{i, t}-\sum_{j=1}^{n z} Z_{j} T_{i, t-j \delta}+Y_{o} T_{o, t}+\sum_{j=1}^{n z} Y_{j} T_{o, t-j \delta}+\sum_{j=1}^{n q} \Phi_{j} q_{k i, t-j \delta}^{\prime \prime} \\
\text { For the outside hear flux } \\
q_{k o}^{\prime \prime}(t)=-Y_{o} T_{i, t}-\sum_{j=1}^{n z} Y_{j} T_{i, t-j \delta}+X_{o} T_{o, t}+\sum_{j=1}^{n z} X_{j} T_{o, t-j \delta}+\sum_{j=1}^{n q} \Phi_{j} q_{k o, t-j \delta}^{\prime \prime}\end{array}$ & $\begin{array}{l}\text { Similar approach } \\
\text { with small } \\
\text { differences listed } \\
\text { below. }\end{array}$ \\
\hline & $\begin{array}{l}\text { Heat flux at a single previous time step, so that } \\
\text { more numbers of significant CTF are needed. } \\
\text { Fixed hourly time step }\end{array}$ & $\begin{array}{l}\text { Heat fluxes at multiple previous time steps, so that less } \\
\text { numbers of significant CTF are needed. } \\
\text { Time step varies from } 1 \text { minute to } 1 \text { hour }\end{array}$ & \\
\hline CondFD & & $\begin{array}{l}\text { Crank-Nicholson } \\
\qquad \begin{array}{r}C_{p} \rho \Delta \mathrm{x} \frac{T_{i}^{j+1}-T_{i}^{j}}{\Delta t}=\frac{1}{2}\left[\begin{array}{r}\left(k_{W} \frac{\left(T_{i+1}^{j+1}-T_{i}^{j+1}\right)}{\Delta \mathrm{x}}+k_{\mathrm{E}} \frac{\left(T_{i-1}^{j+1}-T_{i}^{j+1}\right)}{\Delta \mathrm{x}}\right) \\
+\left(k_{W} \frac{\left(T_{i+1}^{j}-T_{i}^{j}\right)}{\Delta \mathrm{x}}+k_{E} \frac{\left(T_{i-1}^{j}-T_{i}^{j}\right)}{\Delta \mathrm{x}}\right)\end{array}\right] \\
\text { Adams-Moulton }\end{array} \\
C_{p} \rho \Delta \mathrm{x} \frac{T_{i}^{j+1}-T_{i}^{j}}{\Delta t}=\left(k_{W} \frac{\left(T_{i+1}^{j+1}-T_{i}^{j+1}\right)}{\Delta \mathrm{x}}+k_{E} \frac{\left(T_{i-1}^{j+1}-T_{i}^{j+1}\right)}{\Delta \mathrm{x}}\right)\end{array}$ & $\begin{array}{l}\text { Conduction finite } \\
\text { difference method } \\
\text { allows variable } \\
\text { material properties, } \\
\text { such as k and Cp } \\
\text { (PCM simulation) }\end{array}$ \\
\hline
\end{tabular}




\begin{tabular}{|c|c|c|c|}
\hline $\begin{array}{l}6.4 \\
\text { Convection }\end{array}$ & $\begin{array}{l}\text { Natural and forced convection in Table } 1 \\
\text { Natural convection: Horizontal, vertical and } \\
\text { tilted surface } \\
\text { Forced convection: based on Nu number }\end{array}$ & $\begin{array}{l}\text { Inside: Simple, TARP, CeilingDiffuser, } \\
\text { AdaptiveConvectionAlgorithm } \\
\text { Outside: SimpleCombined, TARP, MoWiTT, DOE-2, } \\
\text { AdaptiveConvectionAlgorithm }\end{array}$ & $\begin{array}{l}\text { E+ can either adopt } \\
\text { AtticSim or use its } \\
\text { own }\end{array}$ \\
\hline 6.5 Radiation & $\begin{array}{l}\text { View factor } \\
\text { Calculated internally based on fixed geometry } \\
\text { shape }\end{array}$ & $\begin{array}{l}\text { Approximated method or view factor inputs } \\
\text { The approximated method based on area ratios may be } \\
\text { too simple. } \\
\text { Inputs may be used to provide more accurate view } \\
\text { factors. }\end{array}$ & $\begin{array}{l}\text { E+ will use } \\
\text { Radiance to } \\
\text { calculate view } \\
\text { factors. This } \\
\text { configuration } \\
\text { algebra approach } \\
\text { requires fixed } \\
\text { geometry. } \\
\text { MRT may be better } \\
\text { than the } \\
\text { approximated } \\
\text { method as a } \\
\text { simplified approach }\end{array}$ \\
\hline \multirow[t]{3}{*}{$\begin{array}{l}6.6 \\
\text { Ventilation }\end{array}$} & $\begin{array}{l}\text { The ventilation air is a combination of stack and } \\
\text { wind. } \\
\text { Heat transfer includes multiple surfaces in } \\
\text { contact with ventilation air. }\end{array}$ & $\begin{array}{l}\text { Have multiple ventilation objects to calculate ventilation } \\
\text { rate as a function of temperature, wind speed, and stack } \\
\text { effect. } \\
\text { No heat transfer along flow pathway between surfaces } \\
\text { and ventilation air. }\end{array}$ & $\begin{array}{l}\text { E+ may adopt this } \\
\text { approach. } \\
\text { Authors are unsure } \\
\text { if EnergyPlus } \\
\text { includes heat } \\
\text { transfer between } \\
\text { ventilated air and } \\
\text { surfaces. }\end{array}$ \\
\hline & $\begin{array}{l}\text { Moves air along a flow path and picks up heat by } \\
\text { convection from surrounding surfaces } \\
\qquad \dot{m} C_{p} \frac{d T}{d x}=\sum_{j=1}^{M} A(j) H C(j)(T I S(j)-T)\end{array}$ & No such action, because a lumped zone air is assumed & \\
\hline & $\begin{array}{l}\text { Equal proportions of area of each surface are } \\
\text { contacted as the air flows along a differential } \\
\text { length of its own path. }\end{array}$ & No such formula, because a lumped zone air is assumed & \\
\hline
\end{tabular}




\begin{tabular}{|c|c|c|c|}
\hline & $T=T_{o} \exp (-a x)+b[1-\exp (-a x)]$ & & \\
\hline & $\begin{array}{l}\text { An average air temperature } \\
T A=\int_{0}^{1} T d x=b[1+(\exp (-a)-1) / a]-T_{d} / a[\exp (-a)-1]\end{array}$ & No such formula, because a lumped zone air is assumed & \\
\hline \multirow[t]{2}{*}{ 6.7 Moisture } & $\begin{array}{l}\text { Approximation to include latent effects due to } \\
\text { sorption and desorption at the interior surfaces. } \\
\text { Steady-state zone air moisture balance } \\
\sum_{j=1}^{M} A(j) \operatorname{Perm}(j)\left(P(j)-P_{a}\right)+\dot{m}_{v}\left(\omega_{o}-\omega_{a}\right)+\dot{m}_{E}\left(\omega_{i}-\omega_{a}\right) \\
\qquad+\sum_{i=1}^{M} h_{w}(j) A^{\prime}(j)\left(\omega_{s}(j)-\omega_{a}\right)=0\end{array}$ & 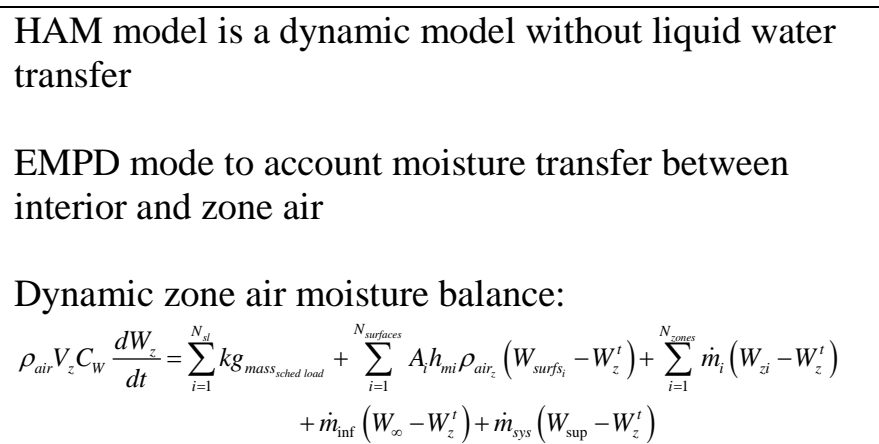 & $\begin{array}{l}\text { E+ is better in } \\
\text { dealing with } \\
\text { moisture transfer } \\
\text { The EMPD model } \\
\text { is similar to } \\
\text { AtticSim }\end{array}$ \\
\hline & $\begin{array}{l}\text { Equation to calculate humidity ratio at the } \\
\text { interior surface } \\
\omega_{s}=\left(b+c \cdot u+d \cdot u^{2}+e \cdot u^{3}\right) \exp (T / a)\end{array}$ & $\begin{array}{l}\text { E+ has two moisture models: EMPD and HAMT } \\
\text { EMPD: } \\
\left(A_{i} \rho_{b} \delta_{M} A_{I}\right)_{i} \frac{d W_{i}^{*}}{d \tau}=h_{M, i} A_{i}\left(W_{r}-W_{i}^{*}\right)+\left(A \rho_{b} \delta_{M} B_{\rho}\right)_{i} \frac{d T_{i}^{*}}{d \tau} \\
\text { HAMT: } \\
\frac{\partial H}{\partial T} \frac{\partial T}{\partial \tau}=\frac{\partial}{\partial x}\left(k^{w} \frac{\partial T}{\partial x}\right)+h_{v} \frac{\partial}{\partial x}\left(\frac{\delta}{\mu} \frac{\partial T}{\partial x}\right) \\
\frac{\partial w}{\partial \phi} \frac{\partial \phi}{\partial \tau}=\frac{\partial}{\partial x}\left(D^{w} \frac{\partial w}{\partial \phi} \frac{\partial \phi}{\partial x}\right)+\frac{\partial}{\partial x}\left(\frac{\delta}{\mu} \frac{\partial T}{\partial x}\right)\end{array}$ & $\begin{array}{l}\text { EnergyPlus has } \\
\text { better moisture } \\
\text { transfer models. }\end{array}$ \\
\hline $\begin{array}{l}6.8 \text { Heat } \\
\text { balances }\end{array}$ & $\begin{array}{l}\text { Attic air heat balance Eq. (46) seems steady } \\
\text { state. } \\
\qquad \begin{array}{l}\sum_{i=1}^{M} A(i) H C(i) T I S(i, 0)-\frac{C_{1}}{1+C_{2} C_{3}} T A \\
\qquad=\dot{m}_{v} C_{p} T_{o} \frac{C_{3}}{1+C_{2} C_{3}}\end{array}\end{array}$ & $\begin{array}{l}\text { Thermal capacity of zone air is included with } 3 \\
\text { approaches to solve the } 1^{\text {st }} \text { ODE numerically: } 3^{\text {rd }} \text { order, } \\
\text { analytical and Euler } \\
\text { Zone air multiplier is allowed to include thermal mass } \\
\text { impact from others. }\end{array}$ & $\begin{array}{l}\text { Thermal capacity } \\
\text { of zone air should } \\
\text { be included. }\end{array}$ \\
\hline
\end{tabular}




\begin{tabular}{|c|c|c|c|}
\hline & & $\begin{aligned} C_{z} \frac{d T_{z}}{d t}= & \sum_{i=1}^{N_{s l}} \dot{Q}_{i}+\sum_{i=1}^{N_{\text {surfuces }}} h_{i} A_{i}\left(T_{s i}-T_{z}\right)+\sum_{i=1}^{N_{\text {zones }}} \dot{m}_{i} C_{p}\left(T_{z i}-T_{z}\right) \\
& +\dot{m}_{\mathrm{inf}} C_{p}\left(T_{\infty}-T_{z}\right)+\dot{m}_{\text {sys }} C_{p}\left(T_{\text {sup }}-T_{z}\right)\end{aligned}$ & \\
\hline $\begin{array}{l}\text { Roof-on-a- } \\
\text { roof }\end{array}$ & Above sheathing ventilation & None & $\begin{array}{l}\text { This model is } \\
\text { applied to an air } \\
\text { gap above the attic } \\
\text { ceiling. }\end{array}$ \\
\hline \multicolumn{4}{|l|}{ Appendix } \\
\hline $\begin{array}{l}\mathrm{X} 1 \text { Duct } \\
\text { model }\end{array}$ & $\begin{array}{l}\text { Consider impact of conduction and leakage } \\
\text { Surface convection and radiations are included } \\
\text { No pressure calculation } \\
\text { No air loop connection }\end{array}$ & $\begin{array}{l}\text { An NFP provides a simplified version to deal with } \\
\text { conduction and leakage. All airflow rates are inputs. } \\
\text { AFN model calculates airflows based on pressure } \\
\text { differences and simulates air distribution system losses. } \\
\text { No radiation exchange between duct surface and } \\
\text { surroundings }\end{array}$ & $\begin{array}{l}\text { Enhance E+ } \\
\text { radiation model. }\end{array}$ \\
\hline Inputs & Require more detailed inputs & $\begin{array}{l}\text { Input overall heat transmission coefficients, including R, } \\
\text { inside and outside heat transfer coefficients }\end{array}$ & $\begin{array}{l}\text { E+ may use } \\
\text { existing convection } \\
\text { method for duct } \\
\text { outside face heat } \\
\text { transfer }\end{array}$ \\
\hline $\begin{array}{l}\text { Supply air } \\
\text { rate }\end{array}$ & Input & Take system flow rate as input & \\
\hline Leakage rate & Input & $\begin{array}{l}\text { Calculated based on leakage area and pressure } \\
\text { differences, close to reality }\end{array}$ & $\begin{array}{l}\text { E+ approach more } \\
\text { closely represents } \\
\text { reality for most use } \\
\text { cases (lacking } \\
\text { data). }\end{array}$ \\
\hline $\begin{array}{l}\text { Surrounding } \\
\text { temperature }\end{array}$ & $\begin{array}{l}\text { Calculated using effective temperature } \\
T_{s}=\frac{h_{o} T_{\text {attic }}+\sum_{j=1}^{N} h_{r j} T_{j}}{h_{o}+\sum_{j=1}^{N} h_{r j}}\end{array}$ & Zone air temperature where ducts are located. & \\
\hline Radiation & Assumptions described in Section X 1.3 provide & None & The assumptions \\
\hline
\end{tabular}




\begin{tabular}{|c|c|c|c|}
\hline $\begin{array}{l}\text { view factors } \\
\text { between } \\
\text { ducts and } \\
\text { surrounding } \\
\text { surfaces }\end{array}$ & $\begin{array}{l}\text { realistic way to calculate radiation exchange } \\
\text { between duct surfaces and surroundings }\end{array}$ & & $\begin{array}{l}\text { used in AtticSim } \\
\text { may be applied to } \\
\text { E+ as a future } \\
\text { enhance-ment. }\end{array}$ \\
\hline Convection & Calculated & Input with constant & \\
\hline $\begin{array}{l}\text { System } \\
\text { coupling }\end{array}$ & None & $\begin{array}{l}\text { Allow system coupling with different fan performance: } \\
\text { constant volume, on/off, and VAV }\end{array}$ & $\begin{array}{l}\text { E+ integrated } \\
\text { model provides } \\
\text { interactions }\end{array}$ \\
\hline $\begin{array}{l}\text { Duct } \\
\text { gain/loss } \\
\text { during } \\
\text { system off } \\
\text { time }\end{array}$ & $\begin{array}{l}\text { Calculates duct heat gain/loss even during the } \\
\text { system off time }\end{array}$ & Excluded & $\begin{array}{l}\text { A possible new } \\
\text { feature for } E+\end{array}$ \\
\hline \multicolumn{4}{|l|}{$\begin{array}{l}\text { Advanced } \\
\text { model }\end{array}$} \\
\hline $\begin{array}{l}\text { Attic air } \\
\text { stratification }\end{array}$ & A single zone air. No attic air stratification & A single zone air. No attic air stratification & Need to enhance it \\
\hline
\end{tabular}

Based on observations from the calculation methods of both programs, an important approach to calculate radiation exchange between duct surfaces and surroundings is not available in EnergyPlus.

It may be time consuming to implement AtticSim model in EnergyPlus. The effort may not be justified. Since EnergyPlus itself is a better building simulation tool, it may need a smaller effort to enhance EnergyPlus by adding radiation exchange between duct surfaces and surroundings. After adding radiation exchange, EnergyPlus should present a good attic model, comparable with AtticSim. Relatively, the differences of convection coefficient calculation methods between AtticSim and EnergyPlus may be ignored. 


\section{APPENDIX C: ENERGYPLUS RESULTS COMPARISON}

The EnergyPlus input files developed to perform simulations for model comparisons with AtticSim were based on Version 7.0. The latest public release version as of this publication is Ver. 8.1. The decision was made to use the latest version of EnergyPlus for this report. In order to bridge the analysis between versions, we compared EnergyPlus simulation results between Ver. 7.0 and Ver. 8.1 with 3 different input configurations and 2 weather locations: Chicago and Atlanta. It should be pointed out that the EnergyPlus transition program was used to update input file version from Ver. 7.0 to Ver. 8.1.

Table 5. The three configurations of Airflow Network for comparison of EnergyPlus Results

\begin{tabular}{|l|l|l|l|}
\hline Case & Abbreviation & Description & Note \\
\hline 1 & All & $\begin{array}{l}\text { Perform distribution system calculations during system fan on time } \\
\text { and multizone Airflow driven by wind during system fan off time. }\end{array}$ & $\begin{array}{l}\text { Original } \\
\text { inputs }\end{array}$ \\
\hline 2 & NoAFN & Not perform Airflow Network simulations & \\
\hline 3 & MZOnly & Perform simulations of multizone airflows driven by wind only & \\
\hline
\end{tabular}

The following table provides annual simulation results with 3 cases in Chicago. The heating and cooling energy uses are based on a gas heating coil and DX cooling coil for comparison. The last 2 columns provide percent differences of heating and cooling, respectively. Results from Ver. 7.0 are the bases for comparison. Percent differences are similar in all 3 cases. Therefore, the differences are not from the Airflow Network model.

Table 6. Comparison between EnergyPlus versions for Chicago

\begin{tabular}{|l|l|l|l|l|l|}
\hline Chicago & Case & $\begin{array}{l}\text { Heating } \\
\text { (gas) }\end{array}$ & Cooling & $\begin{array}{l}\text { Heating } \\
\text { (gas) }\end{array}$ & Cooling \\
\hline & & $\mathrm{kWh}$ & $\mathrm{kWh}$ & $\%$ & $\%$ \\
\hline $\begin{array}{l}\text { Version } \\
7.0\end{array}$ & All & 53782185 & 40393952 & & \\
\hline & NoAFN & 57997629 & 39670857 & & \\
\hline & MZOnly & 59067577 & 38761735 & & \\
\hline $\begin{array}{l}\text { Version } \\
8.1\end{array}$ & All & 55798127 & 38774328 & -3.75 & 4.01 \\
\hline & NoAFN & 59774411 & 38144324 & -3.06 & 3.85 \\
\hline & MZOnly & 60818301 & 37396544 & -2.96 & 3.52 \\
\hline
\end{tabular}

The following table provides annual simulation results with 3 cases in Atlanta. The heating and cooling energy uses are based on a gas heating coil and DX cooling coil for comparison. The last 2 columns provide percent differences of heating and cooling, respectively. Results from Ver. 7.0 are the bases for comparison. Percent differences are similar with 3 cases. Again, the differences are not from the Airflow Network model. 
Table 7. Comparison between EnergyPlus versions for Atlanta

\begin{tabular}{|l|l|l|l|l|l|}
\hline Atlanta & & $\begin{array}{l}\text { Heating } \\
\text { (gas) }\end{array}$ & Cooling & $\begin{array}{l}\text { Heating } \\
\text { (gas) }\end{array}$ & Cooling \\
\hline & & kWh & kWh & $\%$ & $\%$ \\
\hline $\begin{array}{l}\text { Version } \\
7.0\end{array}$ & All & 24237363 & 59043888 & & \\
\hline & NoAFN & 27724806 & 57980116 & & \\
\hline & MZOnly & 28149701 & 56867709 & & \\
\hline $\begin{array}{l}\text { Version } \\
8.1\end{array}$ & All & 24935013 & 57052042 & -2.88 & 3.37 \\
\hline & NoAFN & 28351741 & 56188978 & -2.26 & 3.09 \\
\hline & MZOnly & 28762129 & 55250002 & -2.18 & 2.84 \\
\hline
\end{tabular}

EnergyPlus team provides testing reports at every release (http://apps1.eere.energy.gov/buildings/energyplus/energyplus_testing.cfm). Some reports provide historical changes in results for various releases of EnergyPlus. Possible causes between Ver. 7.0 and Ver. 8.1 are listed below, extracted from Table 2: Summary of Pertinent EnergyPlus Changes that were Implemented [18].

Ver. 7.1.0.012: The interpolation of rain and snow flags in the weather data was revised to better match how the other weather data are interpolated. (CR8800)

Ver. 7.2.0.006: The model coefficients for the DOE-2 outside face convection correlations were changed. This had no impact on results for this test suite since the building was intended as a near-adiabatic test cell with cooling loads driven by internal gains. 